\title{
PATHOMORPHOLOGY OF LYSOSOMAL STORAGE INCLUSIONS IN THE RETICULOENDOTHELIAL GELLS OF SPHINGOLIPIDOSES
}

\author{
Kryoshi TAKAHASHI, Kazuo TERASHIMA, HANDo HAKOZAKI, \\ Makoto NAITO ANd Mizu KOJIMA
}

\author{
First Department of Pathology, Fukushima Medical College Fukushima 960
}

\begin{abstract}
For the purpose of clarifying intralysosomal accumulation of intermediary catabolites in the reticuloendothelial cells of sphingolipidoses, 23 cases of Gaucher's disease, 7 of Fabry's disease, 2 of Sandhoff's disease, 4 of generalized gangliosidosis, 2 of Farber's disease and 11 of Niemann-Pick disease were studied histopathologically, histochemically or electron microscopically. In Gaucher cells characteristic of Gaucher's disease, the storage inclusions contained tubules of about 200 to $600 \AA$ in diameter. In Fabry's disease, pleomorphic osmiophilic lamellated inclusions, which were histochemically of heterogenous nature, were stored, while Sandhoff's disease was characterized by accumulation of miniature but somewhat pleomorphic membranous cytoplasmic bodies in foam cells. As for generalized gangliosidosis, vacuolar inclusions similar to those seen in genetic mucopolysaccharidoses accumulated in the infantile type, but Gaucher-like cells predominated in the juvenile type, which contained fibrillar inclusions. In Farber's disease, curvilinear tubular structures were characteristic in the inclusions of foam cells. Myelin-like figures were found in the storage inclusions of Niemann-Pick cells. The variegated inclusions stored in the reticuloendothelial storage cells of these diseases were mostly surrounded by a delimiting membrane and enzyme cytochemically showed localization of acid phosphatase, indicating that they are transformed secondary lysosomes. Possible sources of the inclusions are discussed in most of the diseases.
\end{abstract}

Since the conceptualization of inborn lysosomal disease by Hers in 1965 (9), it has been acknowledged that there are over 40 kinds of the disease categorized under this concept $(10,11,27)$. Together with genetic mucopolysaccharidoses and genetic mucolipidoses, sphingolipidoses are regarded as a major group of inborn lysosomal disease, in almost all of which missing lysosomal hydrolases and the nature of stored materials have been elucidated by a remarkable recent advance in the research field of biochemistry $(10,11,27)$. Most of the sphingolipidoses accompany serious neuronal disturbances, so special attention has been attracted to pathological changes of the central nervous system in these disorders $(2,7,10,32,34,35)$. On the other hand, in Gaucher's disease, Niemann-Pick disease, Fabry's disease, generalized gangliosidosis (GG), Sandhoff's disease, lactosyl ceramidosis, Farber's disease and some other disorders it is known that systemic storage phenomena occur in various visceral organs, particularly in the reticuloendothelial system (RES). However, the current knowledge regarding such storage phenomena in the RES of these diseases is still limited and fragmentary.

Under these circumstances, this investigation was designed to examine patho- 
logically, histochemically and ultrastructurally the storage in the RES of Gaucher's disease, Fabry's disease, Sandhoff's disease, GG, Farber's disease and NiemannPick disease, making a connection with intralysosomal storage of indigestible catabolites in the reticuloendothelial (RE) cells.

\section{MATERIALS AND METHODS}

Table 1 shows a brief summary of the 48 cases of the present series; materials were obtained either by biopsy or at autopsy.

In all the autopsy cases, specimens were taken from various organs and tissues, especially from the RES, and were fixed in 10\% neutral formalin solution. For histochemistry, formalin-calcium, $80 \%$ alcohol or some other fixatives were used and various staining methods for lipids, carbohydrates, mucopolysaccharides or glycopeptides were employed to demonstrate the histochemical characteristics of accumulated materials in tissues (Table 2). As for enzyme histochemistry, activity of acid phosphatase or nonspecific esterase was mainly examined according to the methods already described elsewhere. (28 31).

For electron microscopy, specimens mostly obtained by biopsy or sometimes at autopsy from the various organs and tissues, particularly from the RES, were fixed, dehydrated and embedded in Epon according to the procedures previously described in our papers. Epon-embedded blocks were cut into ultrathin sections and subsequently stained with both uranyl acetate and lead citrate. Observation was done with Hitachi HU-11 type, HS-8 type, Nihondenshi JEM-T7 and 100B electron microscopes. Utilizing the activity of a lysosomal hydrolase, acid phosphatase, as a subcellular marker of lysosomes, enzyme cytochemical detection of this enzyme was done by the method described in detail in our previous papers (27-31).

TABLE 1. Summary of the 48 examined cases and materials available for the present study

\begin{tabular}{lccc}
\hline Diseases & Autopsy & Biopsy & $\left(\mathrm{EM}^{*}\right)$ \\
\hline Gaucher's disease & 21 & 0 & $(5)$ \\
infantile type & 0 & 2 & $(2)$ \\
adult type & 4 & 3 & $(3)$ \\
Fabry's disease & 2 & 0 & $(1)$ \\
Sandhoff's disease & & & $(1)$ \\
Generalized gangliosidosis & 3 & 0 & $(1)$ \\
infantile type & 0 & 1 & $(1)$ \\
juvenile type & 1 & 1 & $(1)$ \\
Farber's disease & & & $(1)$ \\
Niemann-Pick disease & 5 & 1 & $(1)$ \\
type A & 0 & 1 & $(17)$ \\
B & 3 & 0 & 9 \\
\hline Total Number of Cases & 39 & 9 &
\end{tabular}

Note: EM* - electron microscopic observation 


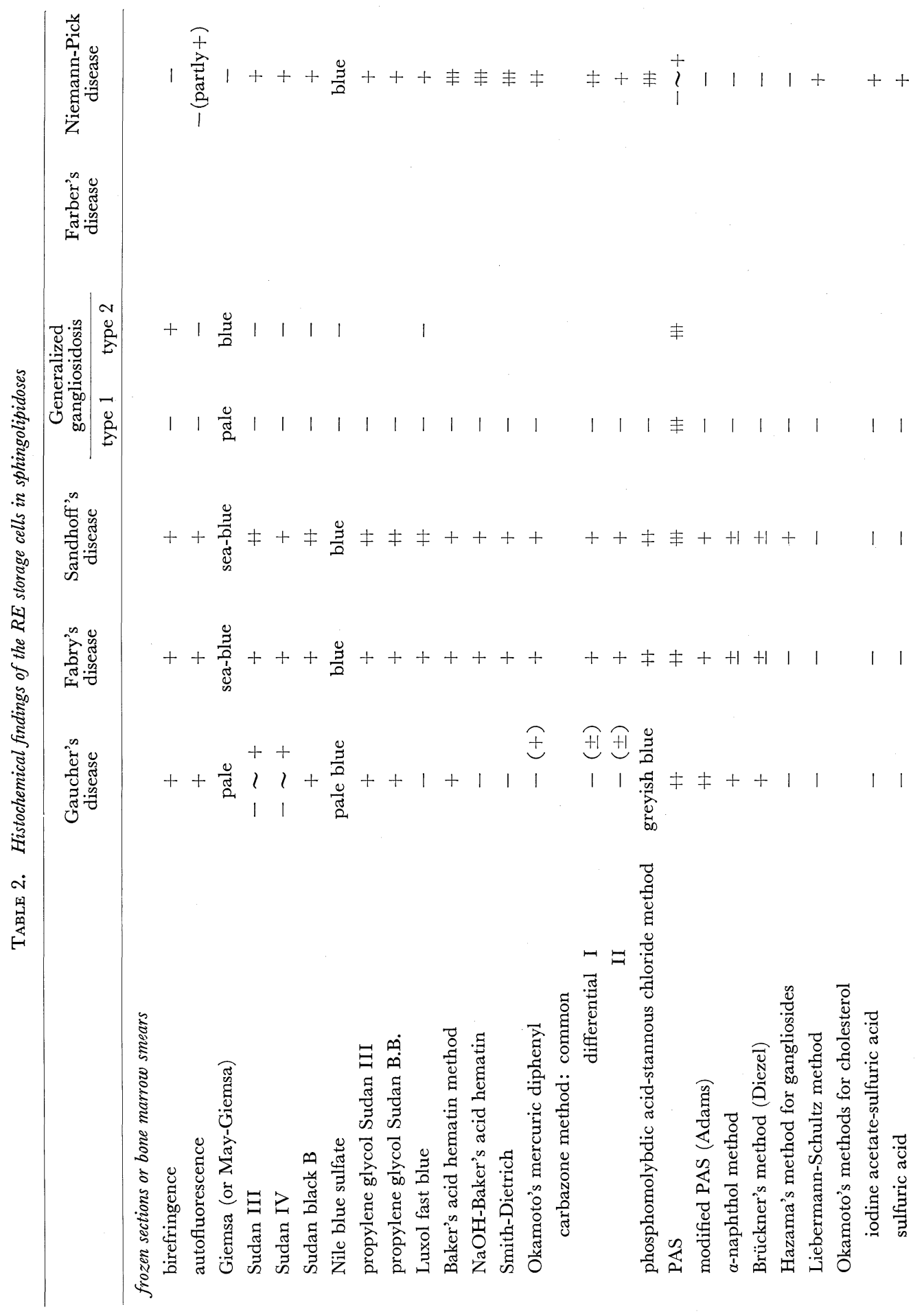




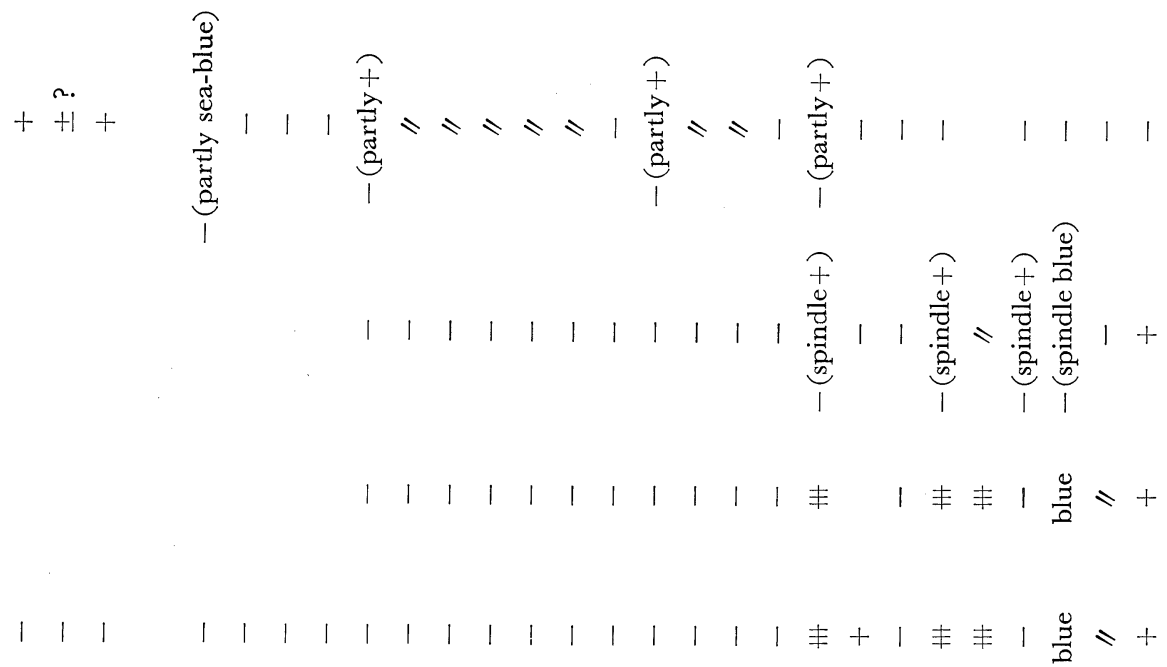

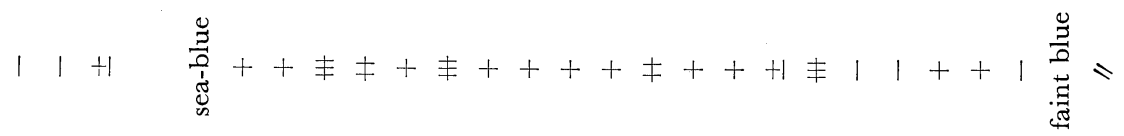

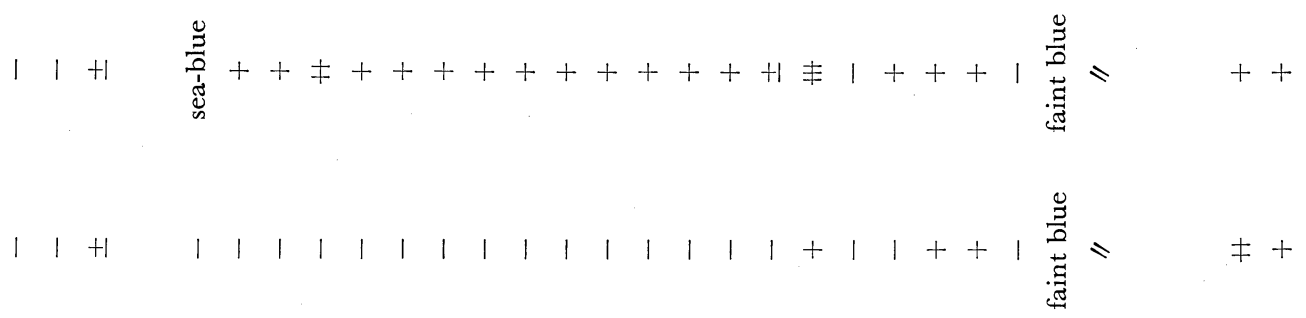

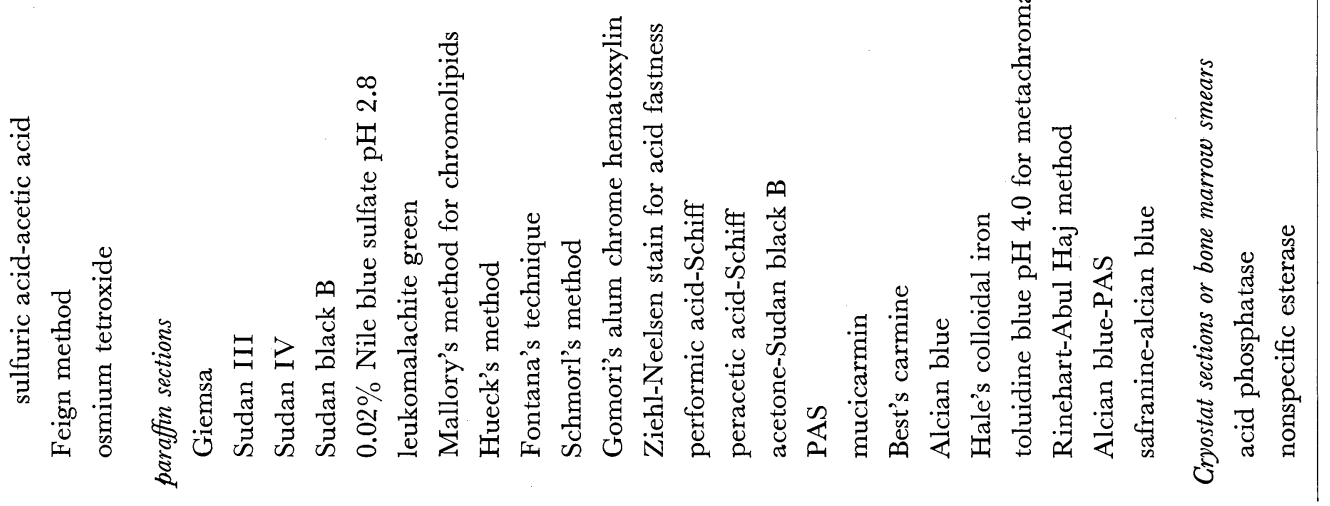




\section{OBSERVATIONS}

\section{Gaucher's Disease (Figs. 1-4)}

Twenty-one autopsy cases of infantile Gaucher's disease and two biopsy cases of adult type were examined. Out of the autopsy cases, 7 were submitted to biochemical study to demonstrate accumulation of glucocerebroside in various visceral organs; in 6 cases in which enzyme assays had been performed, deficiency of $\beta$-glucosidase (glucocerebroside- $\beta$-glucosidase) was confirmed.

Light Microscopy: The striking histological feature of the disease is systemic hyperplasia of the characteristic storage cells conventionally called Gaucher cells throughout the RES, particularly marked in the medullary cords of the spleen, in the parenchyma of lymph nodes and thymus, in the sinusoids of the liver, and in the the bone marrow and pulmonary tissues. Slight to moderate proliferation of Gaucher cells was also found in the reticular zone of the adrenal cortices, tonsilar tissues, or lymphoid follicles of the intestines. Sometimes these cells were found in the perivascular areas of the cerebrum.

The Gaucher cells were large and round, ovoid or polygonal, with abundant pale cytoplasm characterized by the presence of numerous intracytoplasmic striations, giving the apperance of "wrinkled tissue paper" or "crumpled silk". The cytoplasm usually contained one or a few nuclei often situated eccentrically. Multinucleated giant cells were sometimes seen. In addition, phagocytosis of erythrocytes was occasionally confirmed in the Gaucher cells, particularly in those proliferating in the bone marrow and spleen.

Histochemistry: The Gaucher cells were birefringent in polarized light and emitted a yellow autofluorescence in ultraviolet light. With periodic acid-Schiff (PAS) reaction even in paraffin sections, the cytoplasm of these cells stained uniformly. In frozen sections, the modified PAS method after Adams for detection of cerebrosides was also positive but weak sudanophilia was confirmed in stains with various Sudan dyes for lipids. Nile blue sulfate or cresyl violet stain was variable. In frozen sections, $\alpha$-naphthol method and Brückner's reaction (modefied Diezel's reaction) were weakly positive. From these findings, it is clear that the stored material of the Gaucher cells is glycolipid, presumably cerebrosides.

The characteristic intracytoplasmic striations of the Gaucher cells were more clearly demonstrated by Masson's trichrome or Mallory-Azan stain in the paraffin sections. In the spleen and bone marrow, occasional Gaucher cells were positive for Prussian blue method for iron. In addition, the Gaucher cells stained positively with Hale's colloidal iron method, Alcian blue stain, or Rinehart-Abul Haj method for acid mucopolysaccharides.

Acid phosphatase activity was positive in most of the Gaucher cells, particularly in small ones. Nonspecific esterase activity was also moderately positive by the

Figs. 1-4: Gaucher's disease.

FIG. 1. Electron microphotograph of a Gaucher cell. In the cytoplasm there are numerous, irregularly-shaped, mostly membrane-bound inclusions containing tubular structures. $\times 7,000$

Fig. 2. High magnification of tubules measuring approximately 200 to $600 \AA$ in diameter. In the intertubular matrix, ferritin-like particles are visible. $\times 48,000$ Inset; The cross section of tubules shows a circular profile. $\times 50,000$ 

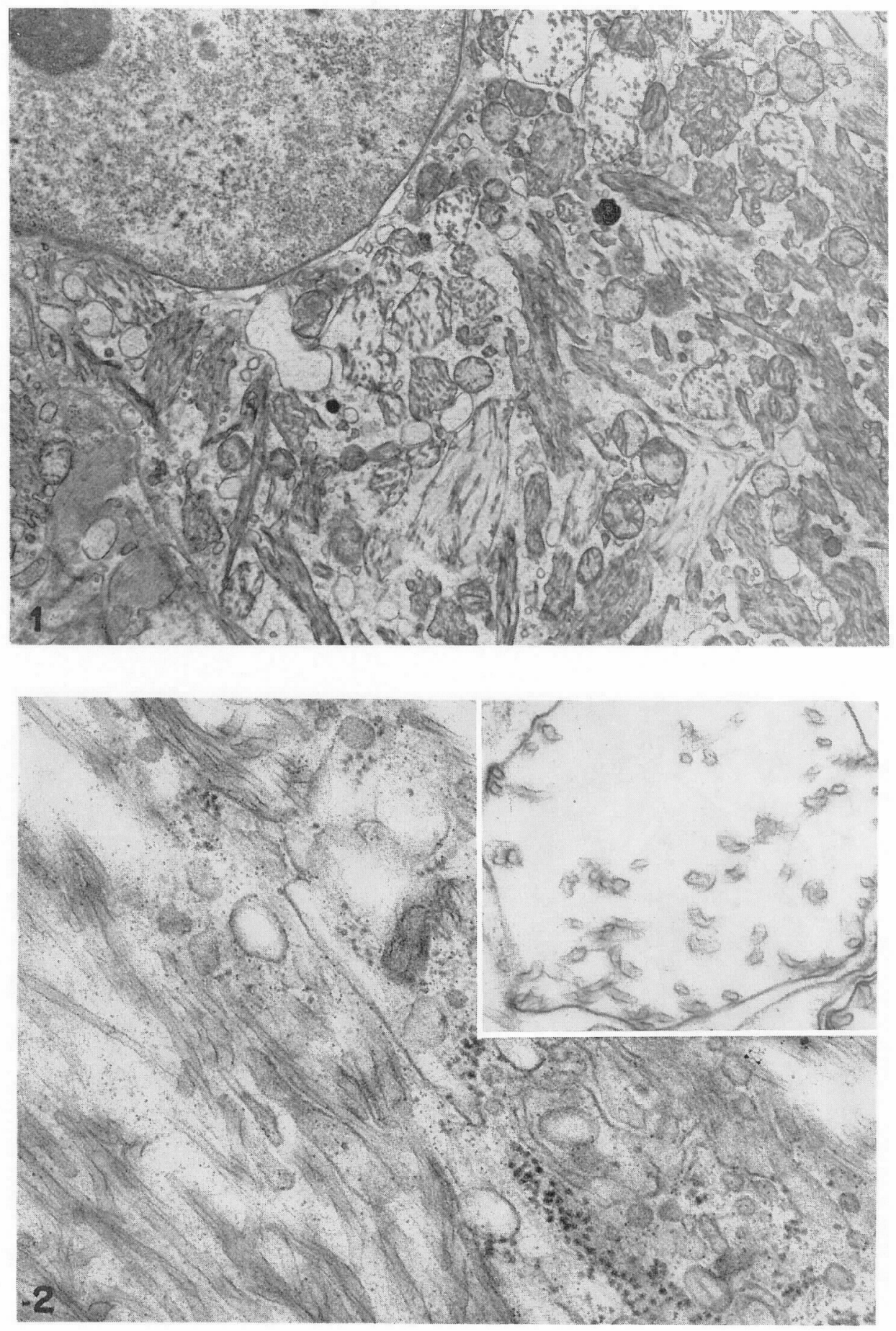

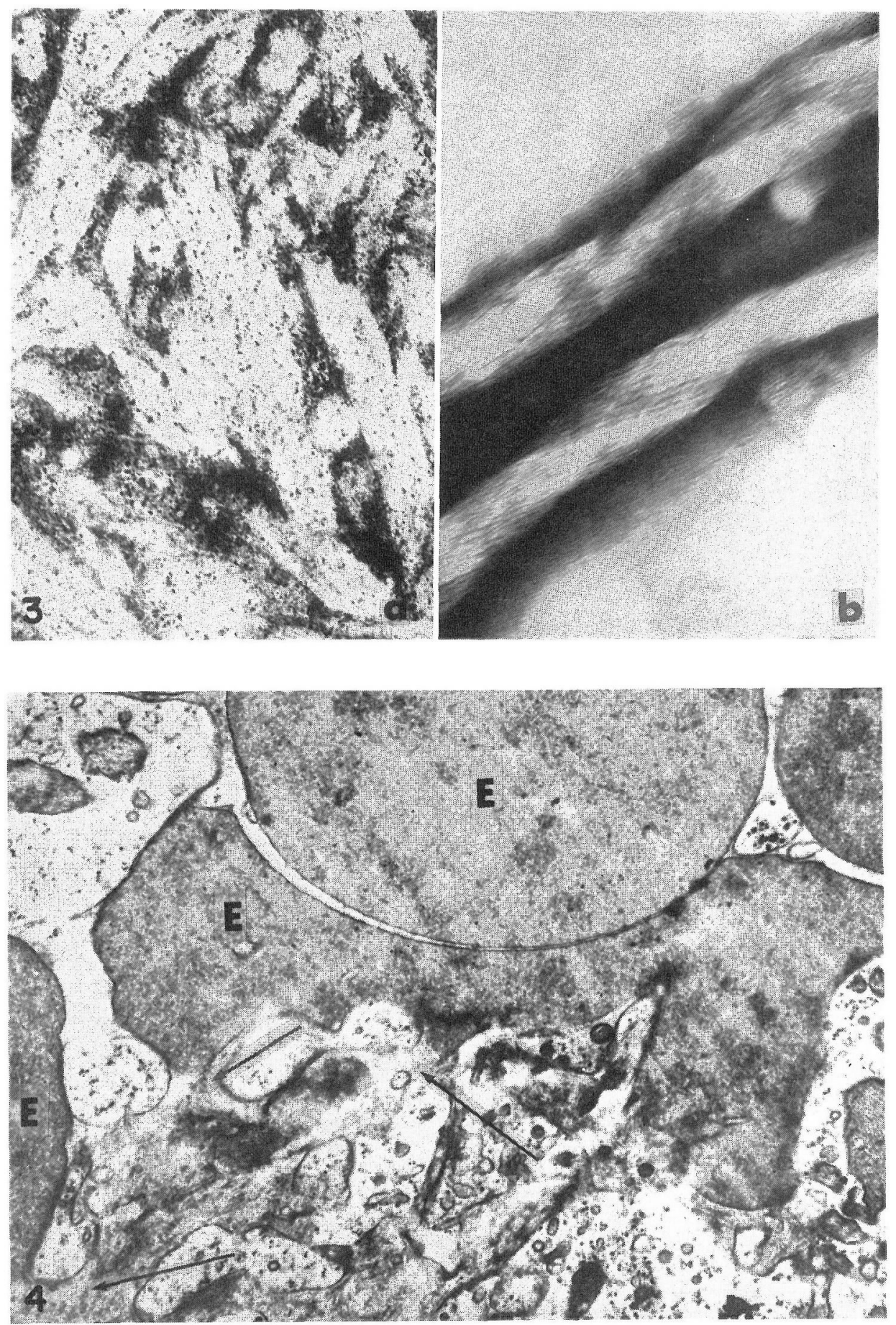
method with $\alpha$-naphthyl butyrate.

Electron Microscopy: Intracytoplasmic inclusions characteristic of the Gaucher cells were extremely variable and irregular in configuration, often showing a mosaic pattern. Most of these inclusions were surrounded by a single unit membrane, but partial disruption or discontinuity of the membrane was sometimes found in larger inclusions. In all the inclusions, a great number of tubules existed running in parallel or slightly undulated. As a rule, the large inclusions had loosely arranged thin-walled tubules in the clear intertubular matrix, while thick tubules were closely packed in the small inclusions with a denser matrix. The tubules measured approximately 200 to $600 \AA$ in diameter and had a ring-like profile in cross section. By electron microscopy after the negative staining method, it was confirmed that each tubule consisted of about 10 fibrils, arranged in parallel, gently twisting in a right-

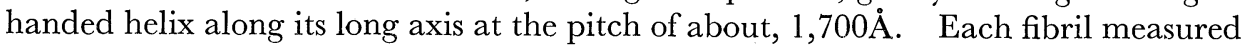
approximately $30 \AA$ in width.

Ultrastructural localization of acid phosphatase activity was demonstrated in or around the inclusions, particularly the intertubular matrix, suggesting that they are of lysosomal origin. However, the large inclusions often showed little or no activity of this enzyme. Some large inclusions located near the cell membrane rarely showed a continuity with the extracellular space through partial disruptions of the cell membrane, a finding which implies that some of the stored materials in the Gaucher cells are secreted to the outside by exocytosis. Actually, a few bundles of tubules were encountered floating in the extracellular spaces.

Occasional phagocytosis of erythrocytes or their fragments was also found in the Gaucher cells, especially in the bone marrow and spleen. On rare occasions, various pictures of continuous transition to the tubular structure within some erythrophagolysosomes were observed, while varying numbers of tubules were seen developing separately in others. In some inclusions, ferritin-like particles were found dispersedly among the tubules. These findings suggest that erythrocytes phagocytized by histiocytes are the major source of the tubular materials stored in the intracytoplasmic inclusions of the Gaucher cells.

\section{Fabry's Disease (Figs. 5-8)}

This study dealt with 4 autopsy and 3 biopsy cases of Fabry's disease. Enzyme assays had been performed in 5 out of the present cases, all of which showed deficiency of $\alpha$-galactosidase. Biochemical studies showed accumulation of trihexosyl ceramide and dehexosyl ceramide in various visceral organs in 2 out of the 4 autopsy cases.

Light Microscopy: Besides the multisystem lipid storage in the neurovisceral organs, light microscopically characterized by prominent cytoplasmic vacuolarization and ballooning of the storage cells, the RES was also widely involved where varying numbers of foam cells proliferated. Except for marked hyperplasia of the

FIG. 3. a. Localization of reaction products of acid phosphatase is intensely found around the storage inclusions as well as spottedly in the intertubular matrix. $\times 10,000 \mathrm{~b}$. High resolution electron microscopy in the negatively stained preparation reveals that each tubule is composed of fibrils arranged in parallel in a gentle right-handed twisting along its long axis. $\quad \times 180,000$

FIG. 4. Erythrophagolysosomes (E) are shown in the Gaucher cell, direct development of the characteristic inclusions is noted by the three black arrows. $\times 4,000$ 
foam cells in the lymph nodes and renal interstitial tissues, the degree of foam cell hyperplasia in other major organs and tissues of the RES was mild as compared to that of Gaucher's disease, Niemann-Pick disease and generalized gangliosidosis. The foam cells were large in general and had abundant ballooned cytoplasm filled by innumerable round vacuoles of varying sizes up to a few microns. In most of the cells, a small pyknotic nucleus was situated in the center of their cytoplasm.

Histochemistry: The stored materials of the foam cells were double-refractile in polarized light and showed a weak to modest sudanophilia in frozen sections stained with different Sudan dyes. Nile blue staining stained them blue. As shown in Table 2, most of the foam cells were weakly positive for Okamoto's mercuric diphenylcarbazone method, Baker's acid hematin method, phosphomolybdic acid-stannous chloride method and Smith-Diretrich method for detection of phospholipids. Luxol fast blue stain was positive in frozen sections, which was preserved to a certain extent in paraffn sections.

In the paraffin sections, the majority of the foam cells were positive for PAS reaction but almost all the foam cells proliferating in the lymphatic sinuses of lymph nodes were PAS-negative. The PAS-positive materials were not digested by the treatment of diastase and also revealed slight sudanophilia even in the paraffin sections. These results indicate that the major component of the storage materials in the foam cells is glycosphingolipids.

Such foam cells often stained blue with Giemsa stain, showing the appearance of sea-blue histiocytes. These sea-blue cells emitted a golden yellow autofluorescence in ultraviolet light and were acid fast in Ziehl-Neelsen stain and positive for $0.02 \%$ Nile blue sulfate stain at $\mathrm{pH} 2.8$, leukomalachite green stain and performic acidSchiff or peracetic acid-Schiff reaction for ceroid, as well as for various staining methods for chromolipids, including Mallory's method, Hueck's method and Schmorl's method. From these findings, it is clear that sea-blue histiocytes bear the histochemical characteristics of ceroid.

Additional histochemical findings included variable positivity of the foam cells in Hale's colloidal iron method, Alcian blue stain and Rinehart-Abul Haj method for acid mucopolysaccharides.

Electron Microscopy: The RE storage cells light microscopically identified as foam cells were characterized by intracytoplasmic accumulation of pleomorphic inclusions. Almost all the small inclusions up to a few microns in diameter were completely surrounded by a single limiting membrane, while in large inclusions over several microns the single membrane often ruptured and disappeared. Such large inclusions displayed irregular configurations. Most of the osmiophilic inclusions consisted of concentric lamellae regularly alternating dark lines of approximately $25 \AA$ with light zones at the periodicity of $40 \AA$. However, different patterns of lamellar arrangement were recognized. For example, inclusions with numerous,

Figs. 5-8: Fabry's disease.

FIG. 5. Eléctron microphotograph of lipid storage histiocytes proliferating in the pulp of lymph node. In these cells, pleomorphic osmiophilic inclusions are abundantly present. $\quad \times 4,500$

FIg. 6. Pleomorphic osmiophilic lamellar inclusions. These inclusions are usually membranebound and show variable patterns of lamellation, such as parallel arrays, concentric lamellae or fingerprint-like pattern. $\quad \times 30,000$ Inset; Reaction products of acid phosphatase is demonstrated in most of the storage inclusions. $\times 13,000$ 

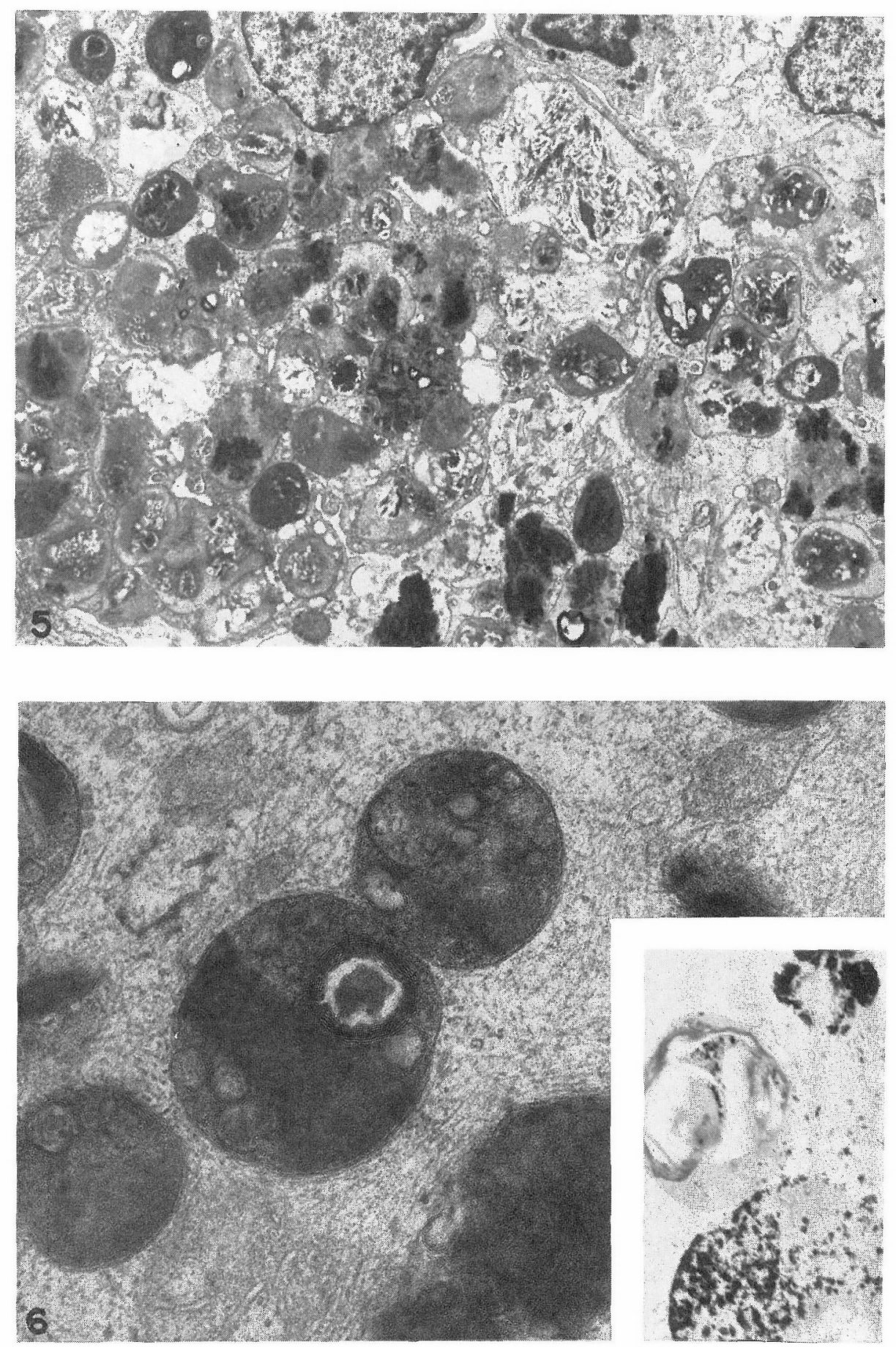

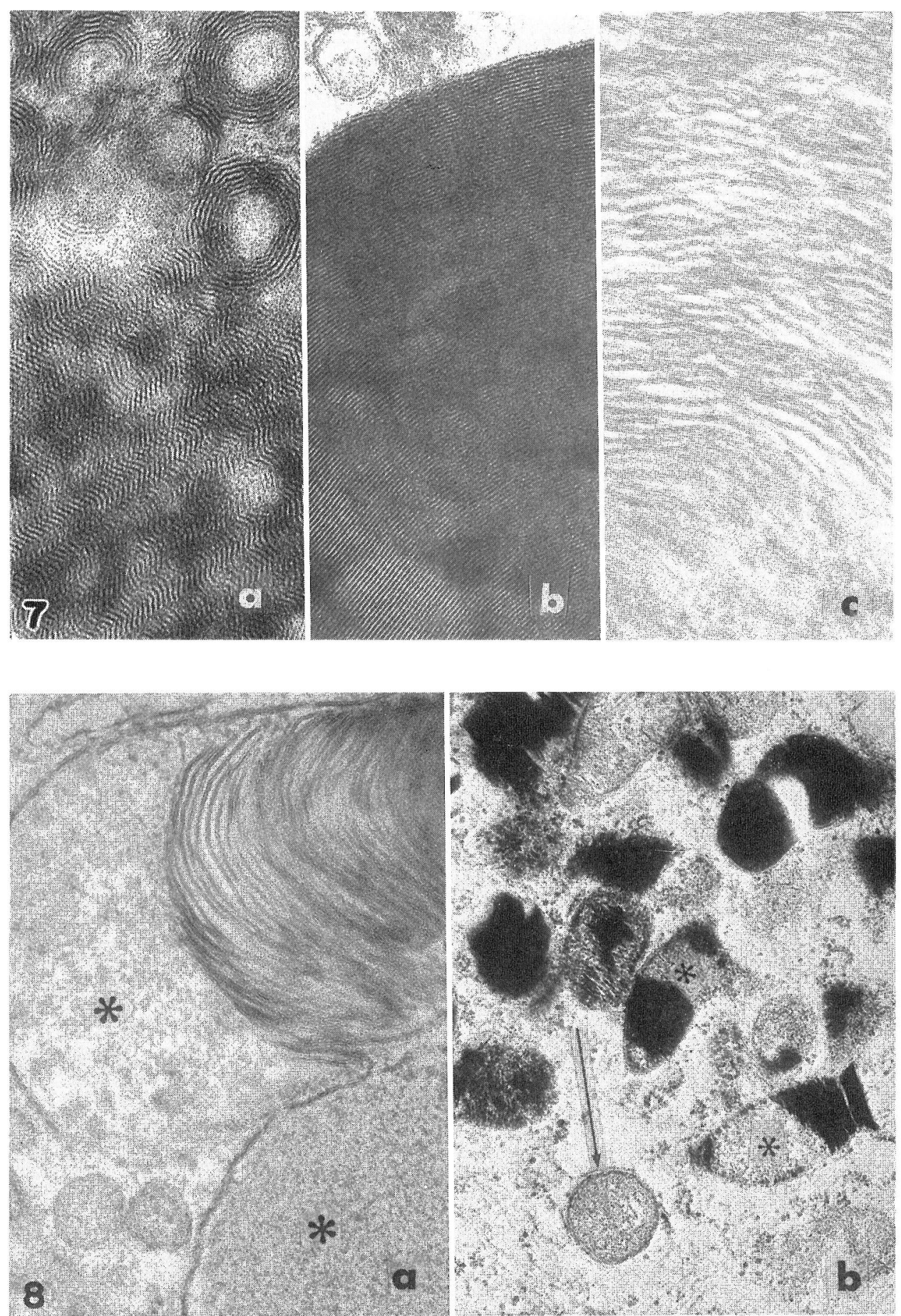
concentrically lamellated spheres revealed a multiple fingerprint-like pattern. On occasion, parallel arrays were seen perpendicularly running towards the limiting membrane. Occasional loosening of the parallel arrays by irregular increases of the light zones in the parallel lamellar inclusions achieved a zebra-like pattern. In the large inclusions, concentric lamellation became rough with undulation of thicker dark lines, giving the appearance of myelin figures to the inclusions. In other inclusions, networks of crossing lammellae or zigzagged patterns of regularly arranged lamellae were occasionally found. A lucent vacuole sometimes appeared in the central core of the regularly and tightly arranged concentric lamellae, while occasional lamellar inclusions contained modestly electron-dense, amorphous materials somewhat similar to those seen in genetic mucopolysaccharidoses.

Enzyme cytochemically, acid phosphatase activity was demonstrated in or around the inclusions, particularly small ones, but it was barely demonstrated in the large inclusions closely packed by abundant lamellar structures. From such localization of acid phosphatase activity in the early stage of storage inclusions, it is suggested that the storage inclusions are of lysosomal origin. In the present observation, stack-like or lamellar structures were occasionally confirmed to develop in mitochondria wrapped by a single unit membrane, showing a gradual transition to the characteristic lamellar inclusion. This finding suggests that at least a part of the pleomorphic osmiophilic inclusions are developed through an autophagic mechanism.

\section{Sandhoff's Disease (Figs. 9-10)}

Two autopsy cases of Sandhoff's disease were examined, one of which was kindly given by the courtesy of Dr. A. Takahashi, Dept. of Pathology, Jichi Med. College (26). In both cases, total deficiency of hexosaminidase A \& B was demonstrated by enzyme assay and excess of $\mathrm{GM}_{2}$-ganglioside, asialo $\mathrm{GM}_{2}$-ganglioside and globoside were biochemically confirmed to be stored in visceral organs in addition to accumulation of $\mathrm{GM}_{2}$-ganglioside in the cerebrum.

Light Microscopy: In addition to prominent cytoplasmic ballooning of neuronal cells in the central nervous system, quite similar to that of Tay-Sachs disease, systemic but mild proliferation of foam cells occurred throughout the RES. In the lymph nodes and spleen, foam cells proliferated sporadically not only in the pulpa but also in the lymphatic follicles, as well as in the germinal centers. Such foam cells were scattered in the bone marrow and occasional foam cell transformation of Kupffer cells was also observed in the hepatic sinusoids.

In most of the foam cells, the cytoplasm showed a yellowish or brownish yellow tinge in $\mathrm{H} \cdot \mathrm{E}$ stain and contained a large number of round lipid materials which had been mostly not dissolved away in the preparation of paraffin sections and in procedures of ordinary staining.

Fig. 7. Variability of lamellar patterns of the inclusions. a. Fingerprint-like pattern and zigzagged lamellae. $\times 120,000$ b. Regular arrangement of concentric lamellae. $\times 120,000$ c. Loosely arranged and somewhat undulated lamellae. $\times 100,000$

Fig. 8. a. These storage inclusions contain a flocculent, finely reticulogranular material (*) besides lamellar structures. $\times 80,000$ b. The black arrow indicates incomplete wrapping of a mitochondrion by a delimiting membrane, the two asteriks show development of myelinated materials in the autophagolysosomes including mitochondria, and their transition to the typical osmiophilic lamellar inclusions is noted. $\quad \times 34,800$ 
Histochemistry: The foam cells emitted a golden yellow autofluorescence in ultraviolet light and stained modestly with Sudan IV and Sudan III, strongly with Sudan black B and blue with Nile blue in frozen sections. The stored lipid materials of the foam cells were fairly positive for PAS reaction after diastase digestion in the paraffin sections and stained faintly with the modified PAS method of Adams in the frozen sections. That the foam cells stained brilliant blue with Luxol fast blue in the paraffin sections is one of the characteristic features.

In both the frozen and paraffin sections, almost all the foam cells stained marine blue with Giemsa, showing the typical appearance of sea-blue histiocytes. In addition to a positive reaction of various stains for chromolipids, these histiocytes stained positively with $0.02 \%$ Nile blue sulfate stain at $\mathrm{pH} 2.8$ and leukomalachite green stain specific for ceroid. Sudanophilia of the foam cells was well preserved in the paraffin sections. Furthermore, the foam cells stained positively with Baker's acid hematin method, Smith-Dietrich reaction, Okamoto's mercuric diphenylcarbazone method and with phosphomolybdic acid-stannous chloride method for phospholipids. From these findings it may be suggested that besides the accumulation of glycosphingolipids (probably of protein-bound gangliosides) as a major component, the foam cells store their cytoplasm with insoluble lipids which bear the histochemical features of ceroid and contain phospholipids.

Electron Microscopy: The cytoplasm of the foam cells light microscopically identified contained numerous round lipid inclusions, mostly limited by a single membrane and of moderate to high electron density. In the inclusions, concentric lamellae or parallel arrays were seen occasionally intermixed with variable amounts of low electron-dense, homogenous materials. The concentrically lamellated inclusions were closely similar to the membranous cytoplasmic bodies (MCB) abundantly found in the neuronal cells of Tay-Sachs disease, though smaller than the latter and not closely packed in general. Stack-like structures were often present in the inclusions. In some foam cells, variable numbers of myelin figures were found, which consisted of coarser concentric arrangement of thicker lamellae than those of the above-mentioned MCB-like inclusions. Moderately electron-dense lipid droplets were often coexistent.

\section{Generalized Gangliosidosis (GG) (Figs. 11-15)}

Three autopsy cases of the infantile type and one biopsy case of the juvenile type were examined. Out of these cases, enzyme assays had been performed in three cases to demonstrate deficiency of $\beta$-galactosidase. In two of the autopsy cases, biochemical analysis had been made on the cerebral tissue to clarify accumulation of $\mathrm{GM}_{1}$-ganglioside. Biochemical identification of acid mucopolysaccharides or glycopeptides in the liver tissue from two autopsy cases is in progress at the Dept. of Biochemistry, Fukushima Medical College.

Figs. 9-10: Sandhoff's disease

Fig. 9. Storage histiocytes in the pulp of lymph node. The storage inclusions are usually membrane-bound, some of which are pleomorphic (arrows). Myelinated materials resembling membranous cytoplasmic bodies are also present $(*) \quad \times 3,800$

Fig. 10. a. Miniature membranous cytoplasmic bodies predominated in this storage histiocytes. $\times 2,000$ b. High magnification of a membranous cytoplasmic body. $\times 30,000$ 

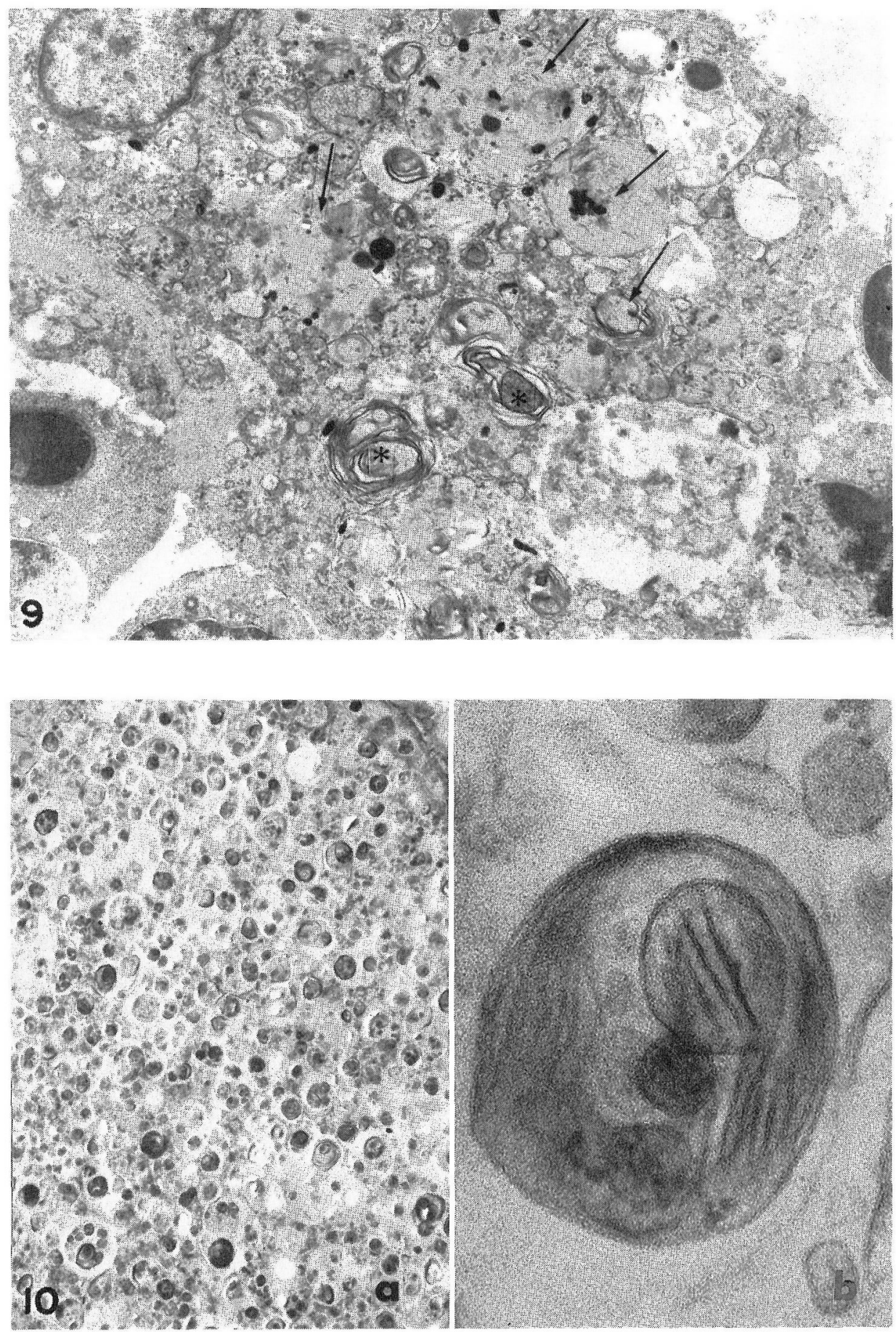

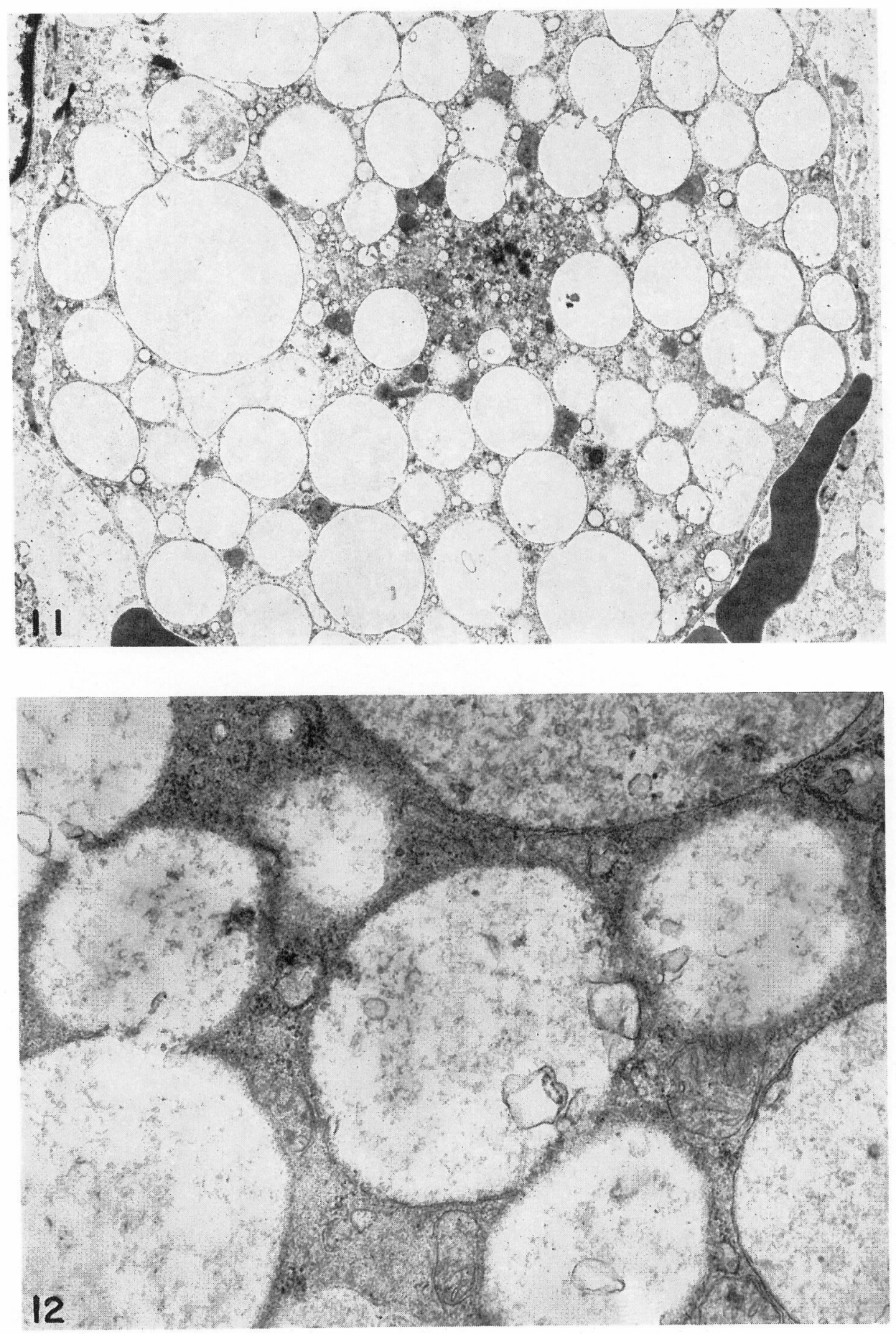
Light Microscopy: In all three autopsy cases of infantile GG, systemic hyperplasia of foam cells was observed throughout the RES, particularly in the parenchyma of lymph nodes, bone marrow and thymus, in both the medullary cords and lymphatic follicles of the spleen, in the sinusoids of the liver, in the mucous membrane and lymphatic follicles of the intestines, as well as in the pulmonary tissue. The foam cells were large with abundant swollen cytoplasm filled with a great number of fine vacuoles.

In sharp contrast to the foam cells, a large number of peculiar storage cells were found in the smears of bone marrow aspiration from a patient with juvenile GG. These storage cells closely resembled the Gaucher cells because of prominent intracytoplasmic striations. In May-Giemsa stain, many of these Gaucher-like cells stained deeply blue.

Histochemistry: The storage cells of both foam cell and Gaucher-like cell types showed no sudanophilia in frozen sections stained with various Sudan dyes but stained positively with PAS reaction, Alcian blue stain or Hale's colloidal iron method, and blue with Rinehart-Abul Haj method or safranine-Alcian blue method. However, no metachromasia was noted in toluidine blue method in acidic ranges. These results may indicate that the stored materials of the RE storage cells are non-sulfated acid mucopolysaccharides or glycopeptides.

Electron Microscopy: The cytoplasm of the foam cells was filled with innumerable membrane-bound vacuolar inclusions, mostly round or somewhat ovoid in configuration, containing variable amounts of flocculent, finely reticulogranular materials usually seen in genetic mucopolysaccharidoses, such as Hurler's, Hunter's or Sanfilippo's syndromes. Some inclusions were empty and often contained ringed or poorly-oriented lamellae. Generally speaking, however, the intracytoplasmic storage inclusions of the foam cells revealed less marked polymorphism. Among the storage inclusions, vesicles, including pinocytic ones, were abundant.

In contrast, the Gaucher-like cells contained a large number of variable-shaped, irregularly outlined inclusions of moderate electron density. These intracytoplasmic inclusions were as a rule surrounded by a single unit membrane, but it appeared partially disrupted or completely lost, sometimes allowing the inclusions to be freely distributed in the cytoplasm. The configuration and distribution pattern of the inclusions was quite similar to those of the inclusions characteristic of the Gaucher cells, so that the Gaucher-like cells appearing in the juvenile GG are indistinguishable from the Gaucher cells under a low power electron microscope. Unlike the tubules found in the inclusions of the Gacuher cells, fibrillar materials predominated in those of the Gaucher-like cells and ran straightly in parallel or somewhat complexly. Among the materials, tubular structures were sometimes intermingled. The electron microscopy with negative staining technique provided more clearly evidence that the stored materials in the Gaucher-like cells were basically composed of fibrils which measured approximately $70 \AA$ wide. In transverse sections, they had no circular profiles. Each interfibrillar space was about $40 \AA$ wide.

Figs. 11-12: Generalized gangliosidosis, infantile type.

Fig. 11. In the swollen Kupffer cell, numerous, membrane-bound, vacuolar inclusions are present, among which there are many vesicles. $\times 6,500$

Fig. 12. High magnification of the vacuolar inclusions surrounded by a single unit membrane and containing a flocculent, finely reticulogranular material. $\times 24,000$ 

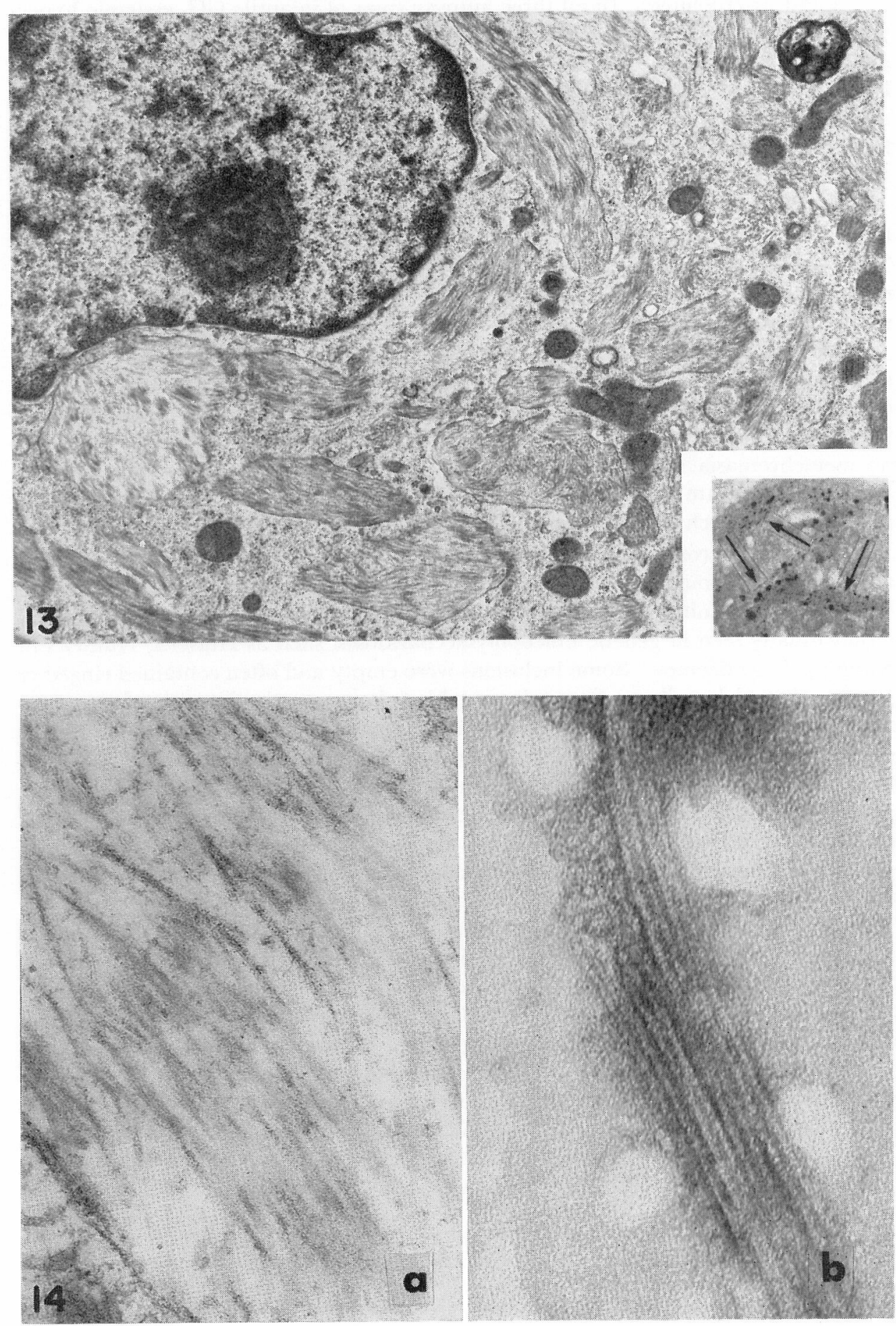

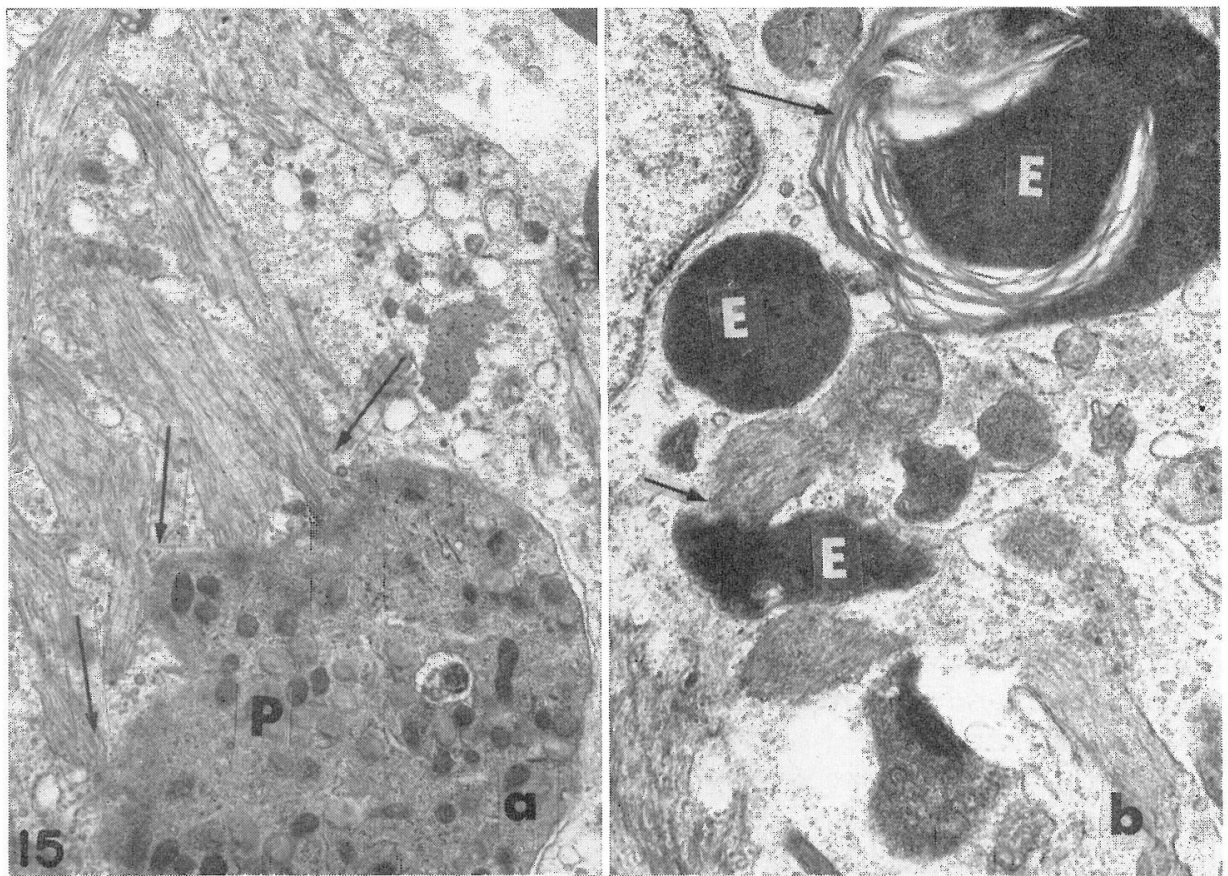

FIG. 15. a. Note direct development of fibrillar materials from the engulfed platelet (three black arrows) $\times 13,000$ b. Note erythrophagolysosomes $(\mathrm{E})$ in the Gaucher-like cell and gradual transition or direct development of fibrillar inclusions from these phagolysosomes (arrows). $\times 7,000$

Enzyme cytochemistry revealed activity of acid phosphatase in small inclusions, suggesting that the storage inclusions are of lysosomal origin. However, large inclusions tended to lose the enzyme activity. In the Gaucher-like cells, blood cells were less frequently confirmed to be phagocytized and digested to variable degrees and gradual transition to fibrillar materials from the engulfed blood cells within such heterophagolysosomes was observed.

\section{Farber's Disease (Figs. 16-19)}

Two autopsy cases of this disease were examined in the present study, one of which was the first case in Japan. Biopsy and necropsy materials from this case were kindly given by the courtesy of Dr. T. Tanaka, Central Laboratories, Okayama University. Of the other autopsy case, many microscopic preparations were given by Dr. G. Molz, Pathological Institute of Zürich University (15). In the former

Figs. 13-15: Generalized gangliosidosis, juvenile type.

Fig. 13. This cell closely resembles a Gaucher-like cell, because the stored inclusions are similar in configuration to those of Gaucher cells. These inclusions are bounded by a delimiting membrane and contain fibrillar materials. $\times 7,000$ Inset: The three black arrows indicate localization of acid phosphatase activity in the small storage inclusions. $\quad \times 2,500$

FIG. 14. a. High magnification of the fibrillar material in the inclusions of Gaucher-like cell. $\times 60,000$ b. By high resolution electron microscopy in negative staining preparation, fibrils having the width of roughly $30 \AA$ can be observed. $\times 240,000$ 
case, biochemical analysis was attempted on the subcutaneous granulomatous lesion by Dr. Y. Suzuki, Dept. of Pediatrics, University of Tokyo, who demonstrated accumulation of ceramide in the lesion.

Light Microscopy: The most striking feature of this disease is multifocal development of granulomatous lesions in the periarticular regions, including the joint capsules and adjacent tendons, as well as of subcutaneous nodules. In these lesions, numbers of foam cells were dispersed or proliferated in clusters in fibrous connective tissues. In the early cellular lesions, however, typical foam cells were scant and spindle, elongated or polygonal cells with less marked foamy cytoplasm predominated. The large foam cells in the late fibrous lesions mostly had an abundant clear cytoplasm filled with numberless ill-defined vauoles. In advanced cases, diffuse hyperplasia of similar foam cells was found throughout the RES, particularly in lymph nodes, thymus, liver, bone marrow or spleen.

Histochemistry: The proliferating cells in the early lesions contained variable quantities of PAS-positive materials which were weakly metachromatic in toluidine blue method $\mathrm{pH} 4.0$ and positive for Hale's colloidal iron method, Alcian blue stain, Rinehart-Abul Haj method and safranine-Alcian blue method for detection of acid mucopolysaccharides. From these histochemical findings, it is suggested that the cells contain undersulfated acid mucopolysaccharides and glycopeptides in thier cytoplasm. With progression of the lesions, however, these materials were gradually reduced and finally disappeared in the typical foam cells appearing in the late fibrous lesions. A weakly sudanophilic material increasingly accumulated in the foam cells.

Electron Microscopy: The foam cells contained numerous, membrane-bound intracytoplasmic inclusions, mostly of round or polyhedral configuration and moderate electron density, characterized by the accumulation of curvilinear tubular structures in an electron-lucent matrix. At a high magnification, the characteristic structures were shortly curved tubules measuring approximately $140 \AA$ in diameter, while the lucent matrix was composed of a homogeneously amorphous or flocculent, finely reticulogranular material. An inverse relationship in amount between the curvilinear tubular structures and the lucent matrix is found in each inclusion. Inclusions dominated by the amorphous or flocculent material somewhat resembled those seen in genetic mucopolysaccharidoses.

Small spindle-shaped fibroblast-like cells predominating in the early lesions were inclined to contain lucent inclusions in which curvilinear tubular structures were rarely seen. In these cells, rough endoplasmic reticulum (rER) was well developed and often dilated. The more the cells appeared rounded and swollen, becoming typical foam cells, the more the curvilinear tubular structures increased in amount and the rER inversely reduced in number. In the late fibrous lesions, a certain number of round electron-dense lipid droplets or irregularly shaped myelin-like figures appeared in most of the foam cells.

In addition, zebra body-like inclusions were occasionally encountered in some

Figs. 16-19: Farber's disease.

FIG. 16. Spindle storage cell appearing in the early stage of a granulomatous lesion. In the cell, cytoplasm contains numerous, membrane-bound, vacuolar inclusions. $\times 2,000$

FIg. 17. Typical foam cell characterizing the granulomatous lesion. In its cytoplasm, numerous, membrane-bound storage inclusions are present, all of which contain innumerable curvilinear tubular structures. $\quad \times 5,000$ 

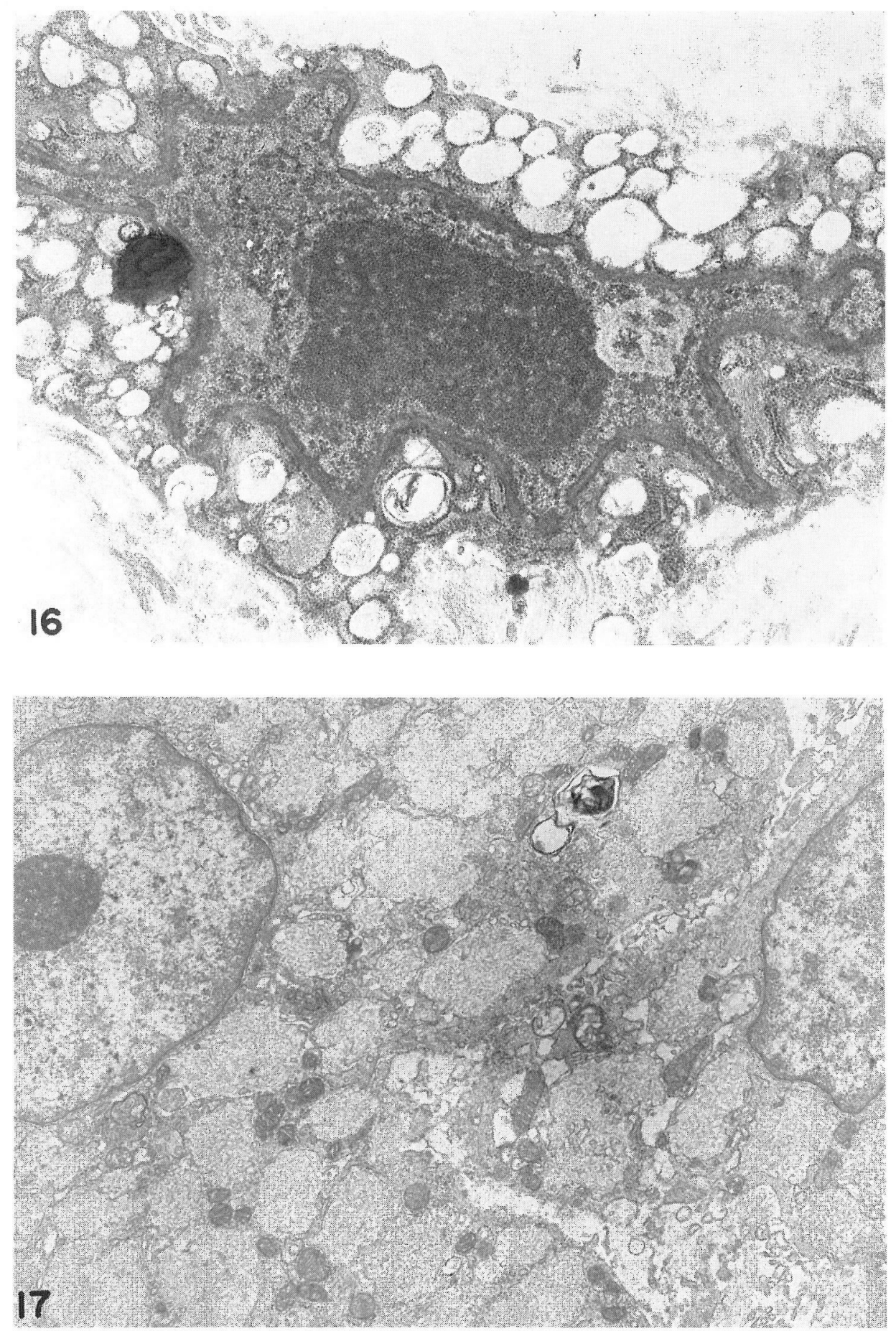

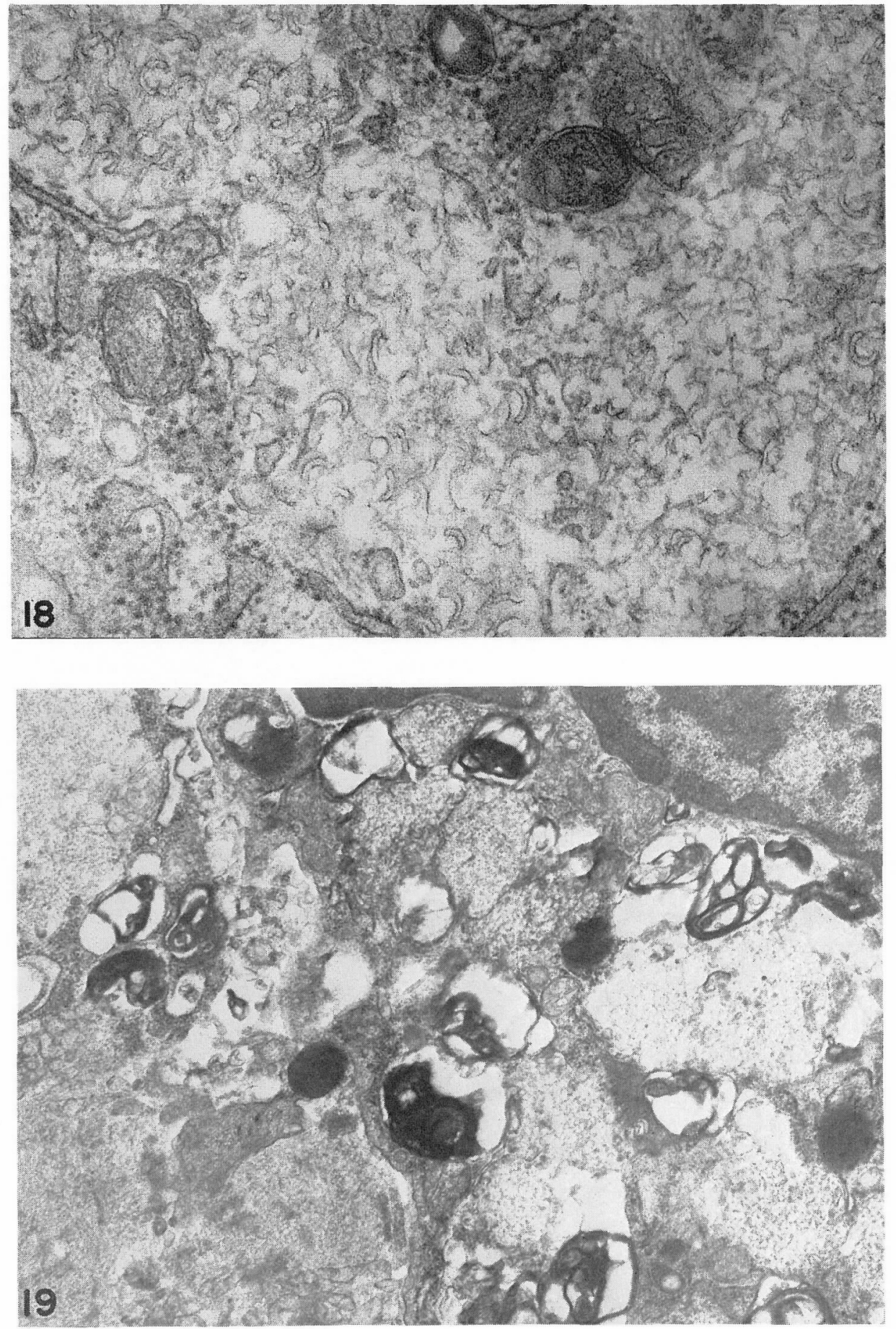
foam cells.

\section{Niemann-Pick Disease (Figs. 20-23)}

As listed in Table 1, 4 autopsy cases and a biopsy case of classical or acute infantile neuropathic type (type A), and a biopsy case of visceral or chronic infantile non-neuropathic type (type B) and an autopsy case of subacute neuropathic type (type $\mathrm{C}$ ) were examined. In two cases of type $\mathrm{A}$ and one of type $\mathrm{B}$, in all of which enzyme assays had been performed, deficiency of sphingomyelinase was demonstrated in leukocytes or cultured fibroblasts. In one of type C, sphingomyelinase activity was normal.

Light Microscopy: In all the different types, numerous foam cells were observed. These cells usually contained a pyknotic nucleus in the center of their swollen cytoplasm which was stuffed with a great number of fine round vacuoles of almost equal size. Because of their bubble soap or mulberry appearance, they are generally called Niemann-Pick cells. The Niemann-Pick cells proliferated remarkably in the RES, particularly in the spleen, lymph nodes, bone marrow, liver, thymus and lungs. In Giemsa stain, almost all the Niemann-Pick cells showed the typical foamy appearance but a small number of sea-blue histiocytes were found sporadically in the type C.

Histochemistry: In such typical Niemann-Pick cells, the stored materials were easily dissolved away in the processing and preparation of paraffin bocks, so they were light microscopically observed as empty vacuoles. In frozen sections after formalin-calcium fixation, these cells stained weakly to modestly positively with various Sudan dyes or with Luxol fast blue, blue or blue violet with Nile blue sulfate and negatively or faintly black with osmium tetroxide method. Furthermore, SmithDietrich method, Baker's acid hematin method, NaOH-Baker method, phosphomolybdic acid-stannous chloride method, and the common, first and second differential methods of Okamoto's mercuric diphenylcarbazone stain for phospholipids were all positive. From these findings, it is obvious that the storage lipid in the NiemannPick cells is phospholipids, mainly sphingomyelin.

In addition to the accumulation of sphingomyelin, simultaneous accumulation of cholesterol esters is suggested because of positive staining reactions of LiebermannSchultz method and Okamoto's strong acid methods for cholesterol. In sea-blue histiocytes, ceroid or its related lipids were histochemically identified.

Electron Microscopy: Numerous osmiophilic inclusions were stored in the cytoplasm of Niemann-Pick cells. These inclusions were round, ovoid or irregular in configuration and varied in size up to several microns. Almost all the inclusions were wrapped by a single limiting membrane and contained single or numerous myelin-like figures made up of tightly or loosely arranged concentric lamellae. High power electron microscopy revealed alternation of a clear zone of about $30 \AA$ in width with a dark line at the periodicity of $50 \AA$ in the tightly arranged concentric lamellar areas. In the loosely arranged areas, however, the clear zone variably increased in width, giving a vacuolar appearance to the inclusions. Such vacuolar inclusions were abundant in the Niemann-Pick cells of the type B. Besides, amorphous or

Fig. 18. Curvilinear tubular structures are usually seen as shortly curved tubules having a width of about $140 \AA$. $\times 42,000$

FIG. 19. In the old foam cell, myelin-like residual bodies are increased in the cytoplasm. $\quad \times 5,000$ 

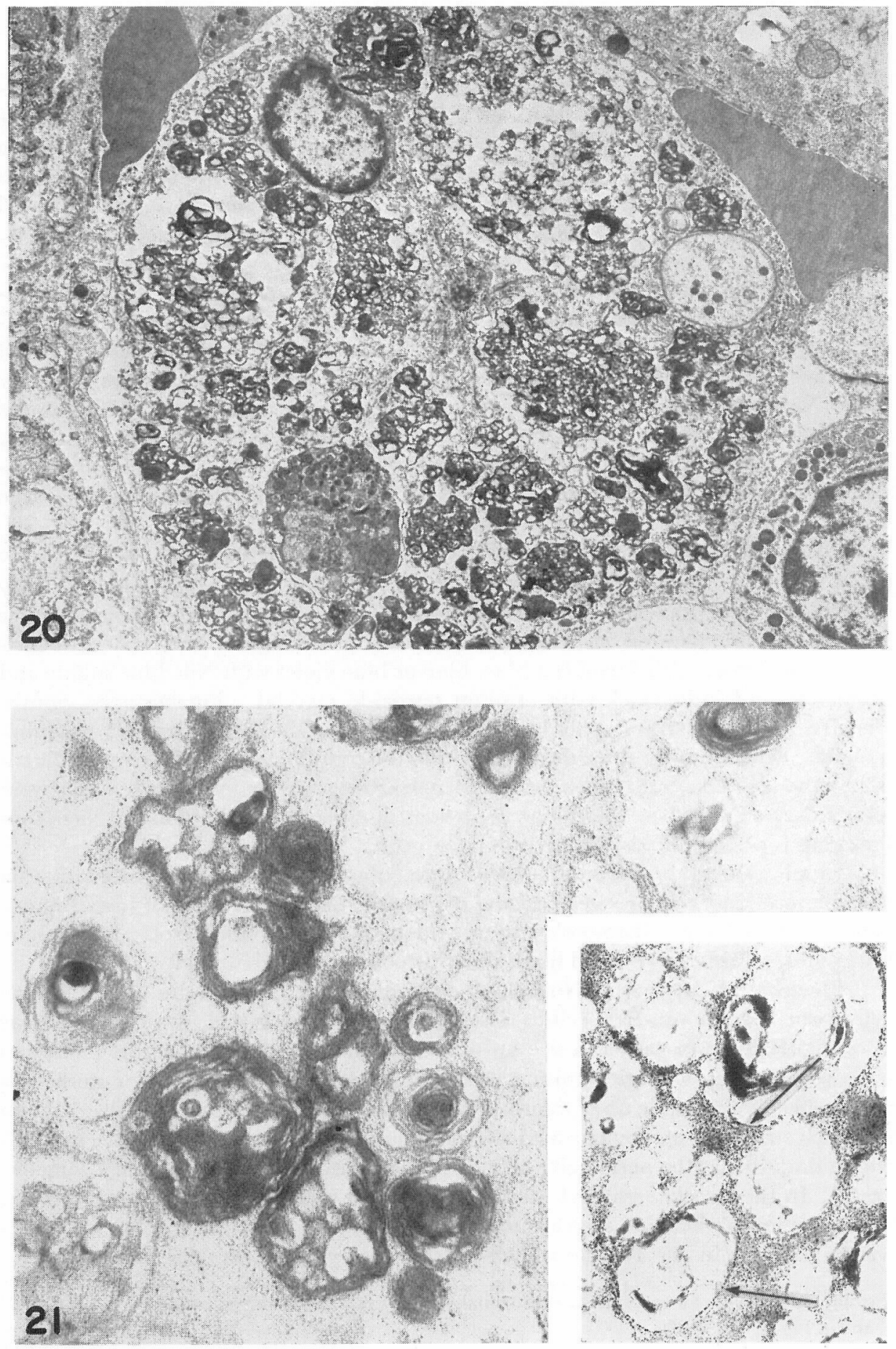

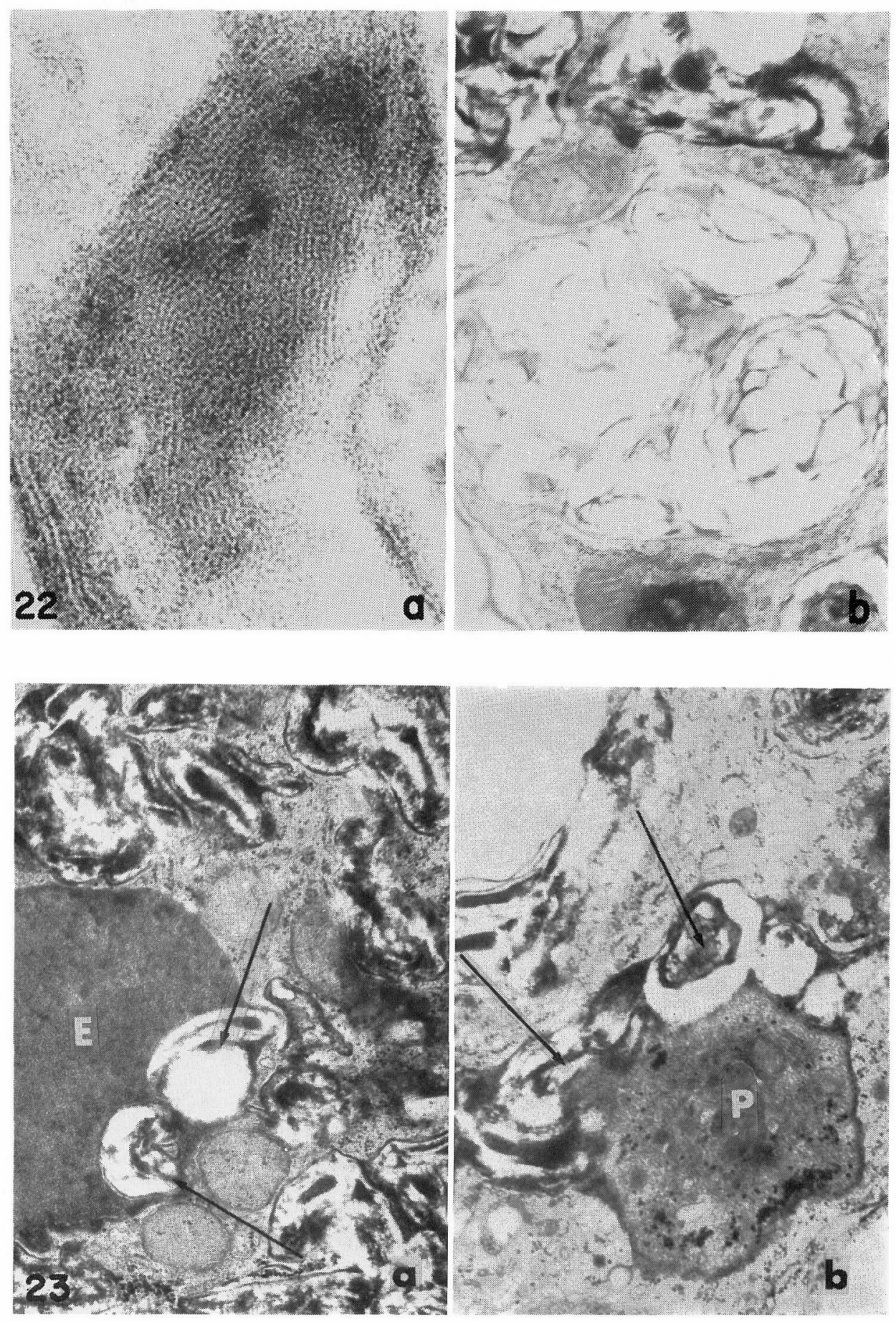
finely granular dense materials were often found in the osmiophilic inclusions.

Enzyme cytochemically, localization of acid phosphatase activity was proved in or around the inclusions, indicating that they are a modified secondary lysosome. It has been preferably explained that the accumulation of sphingomyelin may arise from the turnover of the surface membranes and intracellular components of almost all cells because sphingomyelin is found in the plasma membrane of all kinds of cells and in various intracellular organelles, such as the endoplasmic reticulum and mitochondria (4). Interestingly enough, however, the present observation provided evidences that the accumulating sphingomyelin is derived from blood cells engulfed by Niemann-Pick cells. Namely, gradual transitions and direct development of myelin figures from the ingested blood cells were confirmed in some of the NiemannPick cells.

\section{DISGUSSION}

The present study has revealed the distribution and light microscopical appearance of RE storage cells, as well as histochemical and fine structural features of their stored materials, in the sphingolipidoses involving the RES. Based on the results obtained in this study, discussion will be done about the storage phenomena in the RES of these disorders, particularly focusing on the ultramorphological and histochemical characterization of the stored materials in the RE storage cells and possible mechanism of their intralysosomal accumulation due to the deficit of lysosomal hydrolases.

In Gaucher cells characteristic of Gaucher's disease, excess of glucosyl ceramide is stored, which is currently explained to be caused by a deficiency of glucocerebroside $\beta$-glucosidase $(11,27)$. Ultrastructurally, the basic unit structure of the storage inclusions in the Gaucher cells is considered to be tubules of varying diameters from 200 to $600 \AA$, but high resolution electron microscopy in negatively stained preparations has shown that the tubules are further composed of a subunit, fibrils of roughly $30 \AA$ in width. Although further studies including X-ray diffraction should be performed to determine molecular composition and arrangement of the fibrils, it may be suggested that the fibrils are aggregates of glucosyl ceramide molecules as explained by Lee and his co-workers $(12,13)$, because the width of the fibrils almost corresponds to the length of the molecules (12).

Figs. 20-23: Niemann-Pick disease.

Fig. 20. Electron microphotograph of Niemann-Pick cell. In the cell, numerous, variably-shaped osmiophilic inclusions are present, almost all of which are closely packed with myelin-like figures. $\times 4,800$

Fig. 21. Note a number of myelin-like inclusions found in the Niemann-Pick cell. $\times 12,000$ Inset: As shown by the two black arrows, reaction products of acid phosphatase are localized in the delimiting membrane of the storage inclusions. $\times 10,500$

Fig. 22. a. High magnification of myelin-like figures. A dark line alternates with a clear zone, about $30 \AA$ wide, at a periodicity of approximately $50 \AA$, to compose the myelinated structure. $\times 17,500$ b. Note vacuolation of the myelinated inclusions. $\times 21,000$

FIG. 23. a. On the left side, an erythrophagolysosome (E) is seen in the cytoplasm of a NiemannPick cell, from which two myelin-like figures are developed (arrows). $\times 21,000 \mathrm{~b}$. From the platelet $(\mathrm{P})$ phagocytized by the Niemann-Pick cell, myelin-like figures are developed (arrows) $\times 21,000$ 
In juvenile GG, RE storage cells closely resembling the Gaucher cells appear $(14,17)$. However, in distinction to the tubules stored in the inclusions of Gaucher cells, the stored materials of the Gaucher-like cells in juvenile GG are closely packed by fibrils; this has been more clearly demonstrated by the present high resolution electron microscopy with negative staining technique. In contrast to such Gaucherlike cells, the RE storage cells proliferating in hematopoietic organs of the infantile GG have cell morphology of typical foam cells and their cytoplasm contains numerous membrane-bound, vacuolar inclusions containing flocculent, finely reticulogranular materials which are quite similar in fine structure to those seen in genetic mucopolysaccharidoses, such as Hurler, Hunter or Sanfilippo's syndromes (2, 17, 21, 24, 27, 33). In spite of such a fine structural difference in the storage materials of the RE cells between infantile and juvenile GG, histochemical staining behaviors of the materials were confirmed in the present study to be almost identical for both disorders, suggesting that these are non-sulfated acid mucopolysaccharides or glycopeptides. However, the reason why the storage materials with almost identical histochemical features show such a different ultrastructural morphology between both kinds of the $\mathrm{RE}$ storage cells is an interesting problem left to be solved.

Farber's disease was formerly believed to be a mucopolysaccharidosis $(1,3,11$, 15), because, as observed in the present study, it begins with intracytoplasmic accumulation of undersulfated acid mucopolysaccharides and glycopeptides in the connective tissue cells actively proliferating in the early granulomatous lesions. In the earliest stage of these lesions, the storage cells are electron microscopically similar to those seen in the genetic mucopolysaccharidoses and infantile GG. With progression of the lesions, the characteristic curvilinear tubular structures which are considered to be ultrastructural expression of ceramide accumulation $(5,6,18)$ gradually increase within the vacuolar inclusions of the storage cells. In the late stage, the lesions are filled by numerous foam cells abundantly containing the characteristic inclusions. Recently Sugita et al. (23) and some other investigators (15) have demonstrated deficiency of acid ceramidase in this disease, which may be the cause of ceramide accumulation of the foam cells. However, no adequate explanation has been offered regarding the mechanism of storage of the acid mucopolysaccharides and glycoproteins in the early stage of the disease.

In Niemann-Pick disease, Fabry's disease and Sandhoff's disease, the RE storage cells contain lamellar inclusions of which the interior fine structure differs among these diseases. The storage inclusions of Niemann-Pick cells characteristic of Niemann-Pick disease are characterized by myelin-like figures which are almost common to the already recognized, five different types of the disease, while the foam cells of Fabry's disease contain pleomorphic osmiophilic lamellar inclusions, and in those of Sandhoff's disease, miniature MCBs are predominantly present. The myelin-like figures found in the Niemann-Pick cells usually consist of concentric lamination alternating a dark line with a clear zone having a width of about $30 \AA$ at the peridocity of roughly $50 \AA$. Concerning such lamination of the myelin-like figures, some investigators $(8,22)$ have explained that the width of the clear osmiophobic layers is almost compatible with estimates of the length of the ceramide portion of sphingomyelin and that the osmiophilic layers may correspond to phosphoryl choline, while others have speculated that accumulation of sphingomyelin, cholesterol or a certain other lipid occurs in the interstices of the lamellae made up of proteins $(4,16)$. To 
obtain precise knowledge about what kinds of compounds constitute the myelin-like figures, further correlative electron microscopical and biochemical studies will be required, but the fact that loosening of concentric lamination and vacuolar alteration of the inclusions were observed in Niemann-Pick cells stored with excess of cholesterol may indicate that cholesterol deposition occurs in the interstices of the lamellae (28).

MCB is the characteristic inclusion usually found in the neuronal cells of TaySachs disease and GG and isolation of the MCBs from the brain of Tay-Sachs disease by differential gradient centrifugation and biochemical analysis substantiated that large quantities of $\mathrm{GM}_{2}$ ganglioside were stored in these inclusions $(19,24)$. In Sandhoff's disease, miniature MCBs predominate in the RE storage cells but they often show pleomorphic membranous structures occasionally intermixed with electron-dense lipid bodies. As for the structural composition of the miniature and often pleomorphic $\mathrm{MCBs}$ in the RE storage cells of the disease, $\mathrm{GM}_{2}$ ganglioside and its asialo-derivative, as well as globoside, may be the major component (20) but incorporation of phospholipids or other lipids should be considered from the histochemical evidence presented in this investigation. Moreover, the stored materials bear the histochemical features of ceroid, so it appears that they are possibly produced by hyperoxidation and polymerization of the various sorts of lipids, in combination with proteins. A similar mechanism may be speculated upon in some of the foam cells in Fabry's disease and Niemann-Pick disease. Such foam cells having the histochemical characteristics of ceroid show cell morphology of typical sea-blue histiocyte in Giemsa stained preparations (28-31).

The lamellar inclusions stored in the foam cells of Fabry's disease are called pleomorphic osmiophilic lamellated inclusions, because of their variable patterns of lamellation, such as parallel arrays, round concentric lamination, networks of crossing lamellae, zigzagged arrangement or fingerprint-like pattern (25). Besides these pleomorphic osmiophilic lamellar inclusions, myelin-like figures, electron-dense amorphous materials, flocculent finely reticulogranular materials, or vacuolar structures were randomly coexistent. Histochemically, besides the major component of the glycosphingolipids, the presence of phospholipids, ceroid-like pigments, acid mucopolysaccharides or glycopeptides were also proved, suggesting heterogeneity of the stored materials in the foam cells.

As discussed above, the ultrastructural and histochemical characteristics of the stored materials in the RE storage cells differ from disease to disease. However, all kinds of storage inclusions in the RE cells of these sphingolipidoses are surrounded by a delimiting membrane and show activity of acid phosphatase, a lysosomal hydrolase. From this evidence, it is beyond a doubt that these storage inclusions are transformed secondary lysosomes. This enzyme activity tends to be gradually reduced in intensity and can not be demonstrated within the inclusions which become larger or are closely packed with the accumulating materials. In such large inclusions, occasional disruption or disappearance of the delimiting membrane is encountered.

As for the source of accumulating materials in the RE cells, participation of autophagic mechanism may be suggested in Fabry's disease or Niemann-Pick disease. In Gaucher's disease, derivation of the inclusions from erythrocytes is supported by the ultrastructural transitions between them, the presence of ferritin-like particles and positive iron staining of occasional Gaucher cells. The present observation in juvenile GG and Niemann-Pick disease has shown direct development or gradual transi- 
tion of the stored materials from blood cells phagocytized by the RE cells, indicating that blood cells are at least one of the major sources of the accumulating materials.

\section{ACKNOWLEDGEMENT}

We wish to express our thanks to the following pathologists and doctors who kindly gave us precious biopsy or autopsy materials; Prof. T. Watanuki, Dr. T. Ishidate and Dr. Y. Uesaka, Dept. of Pathology, Akita University; Dr. Y. Urano, Dept. of Pathology, University of Tokyo; Prof. E. Ishikawa and Dr. R. Komori, Dept. of Pathology, Tokyo Jikeikai Medical College; Prof. S. Kawamura, Dept. of Pathology, Toho University; Prof. K. Misugi and Dr. S. Nagaoka, Dept. of Pathology, Yokohama City University; Dr. T. Hisada, Dept. of Pathology, Kanagawa Dental College Dr. H. Uno, Germfree Animal Research Institute, Nagoya University; Profs. N. Ito and H. Kishimoto, and Dr. M. Tatematsu, Dept. of Pathology, Nagoya City University; Dr. A. Takahashi, Dept. of Pathology, Jichi Medical College; Prof. A. Ojima, Dept. of Pathology, Gifu University; Dr. K. Takahashi, Central Laboratory, Kyoto University; Dr. I. Kawahara, Dept. of Pathology, Shinshu University; Prof. Y. Oonishi, Dept. of Pathology, Niigata University; Dr. T. Tanaka, Central Laboratory, Okayama University; Prof. S. Iijima, Drs. H. Hara and K. Namba, Dept. of Pathology, Hiroshima University; Prof. T. Yumoto, Dept. of Pathology, Tottori University; Prof. F. Uchino and Dr. T. Iwata, Dept. of Pathology, Yamaguchi University; Dr. G. Akagi, Dept. of Pathology, Tokushima University; Prof. H. Tsuchiyama and Dr. K. Kawai, Dept. of Pathology, Nagasaki University; Prof. M. Enjoji and Dr. H. Iwasaki, Dept. of Pathology, Kyushu University; Prof. E. Sato, Depı. of Pathology, Kagoshima University; Dr. A. Komiyama, Dept. of Pediatrics, Shinshu University; Dr. H. Sugano, Cancer Institute, Tokyo; Dr. Y. Sasaki, Kanagawa Prefectural Children's Medical Center; Dr. K. Nakamura, National Sendai Hospital; Dr. T. Asao, National Sagamihara Hospital; Dr. E. Chin, Musashino Red Cross Hospital; Dr. H. Hajikano, Kiyose Children Hospital ,Tokyo; Dr. T. Uegusa, Zama Central Hospital; Dr. T. Suzuki, Tokyo Police Hospital; Dr. S. Moriwaki, National Matsuyama Hospital; Dr. H. Shimizu, Kyoto First Red Cross Hospital; Dr. H. Ito, Hyogo Prefectural Children's Hospital; Dr. K. Ishida, Osaka Rōsai Hospital, and Dr. G. Molz, Pathological Institute, Zürich University. We are also greatly indebted to Dr. Y. Koizumi, Pediatric Clinic, and Dr. Y. Yamagata, Clinic of Internal Medicine, Hitachi General Hospital; Dr. N. Izumi, Pediatric Clinic, Ibaragi Prefectural Central Hospital; Dr. Y. Uetani, Himeji Red Cross Hospital, and to Dr. S. Tsuchida, Clinic of Internal Medicine, Yamagata City Hospital, Saiseikan, all of who kindly gave us clinical data of their patients and opportunities of biopsy. Finally we would like to express our thanks to Dr. Y. Suzuki, Dept. of Pediatrics, University of Tokyo, who performed biochemical nanalysis or enzyme assays in many patients of the present series.

\section{REFERENCES}

1. Abul-Haj, S. K., Martz, D. G., Douglas, W. F. and Geppert, L. J.: Farber's disease, report of a case with observations on its histogenesis and notes on the nature of the stored material. $J$. Pediat. 61 ; 221, 1962. 
2. Adachi, M. and Volk, B. W.: Pathology. In the Gangliosidoses, ed. by B. W. Volk and L. Schneck, Plenum Press, New York, 1975. p. 126.

3. Bierman, S. M., Edgington, T., Newcomer, V. D. and Pearson, C. M.: Farber's disease: A disorder of mucopolysaccharide metabolism with articular, respiratory and neurologic manifestation. Arthr. Rheumat. 9; 620, 1966.

4. Brady, R. O. and King, F. M.: Niemann-Pick's disease. In Lysosomes and Storage Diseases, ed. by H. G. Hers and F. van Hoof, Academic Press, New York-London, 1973, p. 439.

5. Dulaney, J., Moser, H. W., Sidbury, J. and Milunsky, A.: The biochemical defect in Farber's disease. In Current Trends in Sphingolipidoses and Allied Disorders, ed. by B. W. Volk and L. Schneck, Adv. Exp. Med. Biol. Plenum Press, New York, 68; 1976, p. 403.

6. Dustin, P., Tondeur, M., Jonniaux, G., Vamos-Hurwitz, E. and Pelc, S.: La maladie de Farber. Etude anatomo-clinique et ultrastructura. Bull. Acad. Med. Belg. 128; 733, 1973.

7. Fredrickson, D. S.: Classification and features of the lipidoses. In Cerebral Lipidoses II, ed. by A. N. Vicente, P. Dustin and A. Lowenthal, Presses Academiques Europennes Bruxelles, 1968, p. 7.

8. Fredrickson, D. S. and Sloan, H. R.: Sphingomyelin lipidoses; Niemann-Pick disease. In the Metabolic Basis of Inherited Disease, ed. by J. B. Stanbury, J. B. Wyngaarden and D. S. Fredrickson, 3rd Edition, McGraw-Hill Book Co., A Blakiston Publication, 1972, p. 783.

9. Hers, H. G.: Inborn lysosomal diseases. Gastroenterology 48; 625, 1965.

10. Hers, H. G.: The concept of inborn lysosomal disease. In Lysosomes and Storage Diseases, ed. by H. G. Hers and F. van Hoof, Academic Press, New York-London, 1973, p. 148.

11. Kojima, M. and Takahashi, K.: Congenital Reticuloendothelial Diseases, Bunkodo Book Co. Tokyo, 1974, p. 143. (in Japanese).

12. Lee, R. E.: The fine structure of the cerebroside occurring in Gaucher's disease. Proc. N. Acad. Sci. 61; 484, 1968.

13. Lee, R. E. and Ellis, L. D.: The storage cells of chronic myelogenous leukemia. Lab. Invest. 24; 261, 1971.

14. Lowden, J. A., Callahan, J. W., Norman, M. G., Thain, M. and Prichard, J. S.: Juvenile GM 1 gangliosidosis. Arch. Neurol. 31; 200, 1974.

15. Molz, G.: Farbersche Krankheit. Pathologisch-anatomische Befunde. Virchows Arch. Abt. A. 344; 86, 1968.

16. Napolitano, L., LeBaron, F. and Scaletti, J.: Preservation of myelin lamellar structure in the absence of lipid. J. Cell Biol. 34; 817, 1967.

17. Petrelli, M. and Blair, J. D.: The liver in $\mathrm{GM}_{1}$ gangliosidosis types 1 and 2. Arch. Pathol. 99; $111,1975$.

18. Rutsaert, J., Tondeur, M., Vamos-Hurwitz, E. and Dustin, P.: The cellular lesions of Farber's disease and their experimental reproduction in tissue culture. Lab. Invest. 36; 474, 1977.

19. Samuels, S., Korey, S. R., Gonatas, J., Terry, R. and Weiss, M.: The membranous granules in Tay-Sachs disease. In Cerebral Sphingolipidoses, ed. by S. M. Aronson and B. W. Volk, Academic Press, New York-London, 1962, p. 309.

20. Sandhoff, K. and Harzer, K.: Total hexosaminidase deficiency in Tay-Sachs disease (variant 0 ). In Lysosomes and Storgae Diseases, ed. by H. G. Hers and F. van Hoof, Academic Press, New York-London, 1973, p. 345.

21. Shimamura, K., Hakazaki, H., Takahashi, K., Kimura, A., Fujino, J., Suzuki, Y. and Nakamura, N.: Sanfilippo B syndrome--A case report-. Acta Path. Jap. 26; 737, 1976.

22. Stoekenius, W.: Osmium tetroxide fixation of lipids. In Proceedings of the European Regional Conference on Electron Microscopy, Nederlandsche Vereniging voor Electronen Microscope, Delft. 1960.

23. Sugita, M., Dulaney, J. T. and Moser, H. W.: Ceramidase deficiency in Farber's disease (lipogranulomatosis). Science 178; 100, 1972.

24. Suzuki, K., Suzuki, K. and Kamoshita, S.: Chemical pathology of $\mathrm{GM}_{1}$ gangliosidosis (generalized gangliosidosis). J. Neuropath. Exp. Neurol. 28; 25, 1969. 
25. Sweely, C. G., Klionsky, B., Krivit, W. and Desnick, R.: Fabry's disease: glycosphingolipid lipidosis. In the Metabolic Basis of Inherited Disease, ed. by J. B. Stanbury, J. B. Wyngaarden and D. S. Fredrickson, 3rd Edition, McGraw-Hill Book Co., A Blakiston Publication, 1972, p. 663 .

26. Takahashi, A., Saito, K. and Koizumi, Y.: An autopsy case of Sandhoff's disease. Beitr. Path. $152 ; 418,1974$.

27. Takahashi, K.: Inborn lysosomal disease involving the reticuloendothelial system. Recent Advances in RES Research 12; 20, 1972.

28. Takahashi, K., Hakozaki, H., Terashima, K. and Kojima, M.: Two distinctive types of lipid histiocytes appearing in the spleen of idiopathic thrombocytopenic purpura-sea-blue histiocyte and foam cell-. Acta Path. Jap. 27; 447, 1977.

29. Takahashi, K., Oka, K., Hakozaki, H. and Kojima, M.: Ceroid-like histiocytic granuloma of the gall-bladder-a previously undescribed lesion-. Acta Path. Jap. 26; 25, 1976.

30. Takahashi, K., Terashima, K. and Hakozaki, H.: Morphological and cytological studies on acquired sea-blue histiocytoses. In the Proceeding of the 16th International Congress of Hematology (Kyoto), Excerpta Medica, Netherlands, 1977, p. 1029-1032.

31. Takahashi, K., Terashima, K., Kojima, M., Yoshida, H. and Kimura, H.: Pathological, histochemical and ultrastructural studies on sea-blue histiocytes and Gaucher-like cells in acquired lipidosis occurring in leukemia. Acta Path. Jap. 27; 773, 1977.

32. Terry, R. D.: Some morphologic aspects of the lipidoses. In Lipid Storage Diseases; Enzymatic Defects and Clinical Implications, ed. by J. Bernsohn and H. J. Grossman, Academic Press, New York-London, 1971, p. 3.

33. Van Hoof, F.: GM $_{1}$-gangliosidosis. In Lysosomes and Storage Diseases, ed. by H. G. Hers and F. van Hoof, Academic Press, New York-London, 1973, p. 305.

34. Volk. B. W., Wallace, B. J. and Aronson, S. M.: Some ultrastructural and histochemical aspects of lipidoses. In Cerebral Lipidoses II, ed. by A. N. Vicente, P. Dustin and A. Lowenthal, Presses Academiques Europennes Bruxelles, 1968, p. 86.

35. Wallace, B. J., Lazarus, S. S. and Volk, B. W.: Electron microscopic and histochemical studies of viscera in lipidoses. In Inborn Disorders of Sphingolipid Metabolism, ed. by S. M. Aronson and V. W. Volk, Pergamon Press, 1966, p. 107. 